NBER WORKING PAPER SERIES

\title{
THE MORE WE DIE, THE MORE WE SELL? A SIMPLE TEST OF THE HOME-MARKET EFFECT
}

Arnaud Costinot

Dave Donaldson

Margaret Kyle

Heidi Williams

Working Paper 22538

http://www.nber.org/papers/w22538

\author{
NATIONAL BUREAU OF ECONOMIC RESEARCH \\ 1050 Massachusetts Avenue \\ Cambridge, MA 02138 \\ August 2016
}

We are very grateful to Manon Costinot, Masao Fukui, Ryan Hill, Anton Popov, Juan Rios, Mahnum Shahzad, and Sophie Sun for excellent research assistance, as well as to David Atkin, Keith Head, David Weinstein, and seminar audiences at the Becker-Friedman Institute, the 2016 IES Summer Workshop, Penn State, Princeton, and the 2016 West Coast Trade Workshop for comments that have improved this work. The construction of some of the data analyzed in this publication was supported by the National Institute on Aging and the NIH Common Fund, Office of the NIH Director, through Grant U01-AG046708 to the National Bureau of Economic Research (NBER); the content is solely the responsibility of the authors and does not necessarily represent the official views of the NIH or NBER. Financial support from NSF Grant Number 1151497, the Hoover IP2 working group, and the Intellectual Property and Markets for Technology Chair at MINES ParisTech is also gratefully acknowledged. Kyle thanks Pfizer for access to the IMS data used. The views expressed herein are those of the authors and do not necessarily reflect the views of the National Bureau of Economic Research.

NBER working papers are circulated for discussion and comment purposes. They have not been peer-reviewed or been subject to the review by the NBER Board of Directors that accompanies official NBER publications.

(C) 2016 by Arnaud Costinot, Dave Donaldson, Margaret Kyle, and Heidi Williams. All rights reserved. Short sections of text, not to exceed two paragraphs, may be quoted without explicit permission provided that full credit, including $\odot$ notice, is given to the source. 
The More We Die, The More We Sell? A Simple Test of the Home-Market Effect Arnaud Costinot, Dave Donaldson, Margaret Kyle, and Heidi Williams NBER Working Paper No. 22538

August 2016

JEL No. F1

\begin{abstract}
$\underline{\text { ABSTRACT }}$
The home-market effect, first hypothesized by Linder (1961) and later formalized by Krugman (1980), is the idea that countries with larger demand for some products at home tend to have larger sales of the same products abroad. In this paper, we develop a simple test of the homemarket effect using detailed drug sales data from the global pharmaceutical industry. The core of our empirical strategy is the observation that a country's exogenous demographic composition can be used as a predictor of the diseases that its inhabitants are most likely to die from and, in turn, the drugs that they are most likely to demand. We find that the correlation between predicted home demand and sales abroad is positive and greater than the correlation between predicted home demand and purchases from abroad. In short, countries tend to be net sellers of the drugs that they demand the most, as predicted by Linder (1961) and Krugman (1980).
\end{abstract}

Arnaud Costinot

Department of Economics, E52-534

MIT

77 Massachusetts Avenue

Cambridge MA 02142

and NBER

costinot@mit.edu

Dave Donaldson

Department of Economics

Stanford University

579 Serra Mall

Stanford, CA 94305

and NBER

ddonald@stanford.edu
Margaret Kyle

MINES ParisTech (CERNA)

and PSL Research University

60 boulevard Saint Michel

75006 Paris

France

margaret.kyle@mines-paristech.fr

Heidi Williams

Department of Economics, E52-440

MIT

77 Massachusetts Avenue

Cambridge MA 02142

and NBER

heidiw@mit.edu 


\section{Introduction}

Do countries with larger domestic markets for some products tend to sell more of the same products in foreign markets? The idea that local demand may stimulate exports is an old one. First hypothesized by Linder (1961) and later formalized by Krugman (1980), the so-called home-market effect has become a central tenet of the new trade theory (Helpman and Krugman, 1985, 1989) and the new economic geography literature (Fujita, Krugman and Venables, 2001). In terms of policy, it implies that import protection may be used as export promotion, a view often more popular in business communities than among economists (Krugman, 1984).

To establish the empirical validity of the home-market effect, one must overcome a key challenge. While theory predicts that the cross-sectional variation in demand causes the pattern of international specialization, observable demand shifters are rarely available in practice. National accounts, for instance, may report how much a country spends on a particular good. But expenditures depend on prices, which themselves depend on supply, not just on demand conditions.

In this paper, we propose a simple test of the home-market effect that uses variation in disease burdens across countries as a way to address this empirical challenge. Our starting point is the observation that countries whose populations are more likely to die from particular diseases, because of exogenous demographic characteristics, are also more likely to demand pharmaceutical treatments that target those diseases. Hence, one can test for the existence of the home-market effect by estimating (i) whether higher disease burdens at home tend to increase the sales of domestic drugs treating those diseases abroad (what we term the weak home-market effect), and if so, (ii) whether they tend to increase them by more than the sales of foreign drugs at home (our strong home-market effect).

To take a concrete example, the drug famotidine (known as Pepcid ${ }^{\circledR}$ in the United States) - used to treat peptic ulcers and gastro-esophageal reflex —was discovered in Japan (Hara, 2003), a country known for particularly high incidence rates of peptic ulcers. ${ }^{1}$ Indeed, in our data, individuals in Japan are nearly twice as likely to die from digestive disorders than are individuals in the rest of the world ( 0.243 deaths per 1,000 population annually in Japan, relative to 0.130 on average in other countries). Our data also suggest that the example of famotidine is not an outlier: sales of Japanese drugs targeting peptic ulcers and gastro-esophageal reflux diseases outside Japan account for $10.35 \%$ of

\footnotetext{
${ }^{1}$ For example, Cleave (1962) notes that the age-adjusted death rate from peptic ulcers for Japanese males in 1954 was 34.7 per 100,000, which can be compared to 14.1 per 100,000 in England and Wales. Cleave discusses the potential role of dietary habits in explaining this pattern.
} 
world sales, compared to an average of $4.54 \%$ for all other disease categories. Our empirical work uses this type of variation-extended to exploit demographic-driven components-in order to test for the home-market effect in a dataset with near-global coverage of drug sales and disease burdens.

The rest of our paper is organized as follows. After discussing the related literature in Section 2, we present a flexible model of drugs supply and demand in Section 3. For expositional purposes, we first study a perfectly competitive environment. In this context, we introduce a simple test of the weak and strong home-market effects based on a loglinear approximation of our model and characterize the conditions for such effects to arise. We then show that the same test remains valid in a range of imperfectly competitive environments, including the one considered in Krugman (1980). Our theoretical analysis highlights the role of sector-level economies of scale, while clarifying that their particular determinants may be irrelevant.

Section 4 describes our data. Our empirical analysis draws on a linkage between two datasets. The first one documents sales in 56 countries of more than 20,000 molecules by roughly 2,650 firms, which we convert to a dataset of bilateral sales at the disease level, by matching each firm to the country in which it is headquartered and each molecule to the disease that it targets. ${ }^{2}$ The second dataset documents the demographic composition of and disease burdens in the same 56 countries, which we use to compute predicted disease burdens by country and disease.

Section 5 presents our main results. Our simple test focuses on a log-linear specification where bilateral sales of drugs targeting different diseases are allowed to depend on disease burdens in the destination country, i.e., the country where drugs are sold; disease burdens in the origin country, i.e., the country where firms selling those drugs are headquartered; and a full vector of disease indicator variables and destination-and-origin indicator variables. Everything else equal, we document that countries tend to sell relatively more of the drugs for which they have higher disease burdens, in line with the existence of a weak home-market effect. Furthermore, the elasticity of sales towards foreign countries tends to be higher than the elasticity of purchases from foreign countries, consistent with the existence of a strong home-market effect.

Section 6 analyzes further the economic determinants of the home-market effect. While the previous results provide empirical support for the notion of a home-market effect in the global pharmaceutical sector, the existence and magnitude of this phenomenon de-

\footnotetext{
${ }^{2}$ Our dataset does not contain information about location of production. Thus, we cannot shed light on whether the home-market effect ultimately operates through exports, foreign direct investment, or a mixture of both. We come back to this point when discussing the related literature in Section 2.
} 
pend, according to our model, on both demand and supply elasticities. Our last results point towards the home-market effect being driven by substantial economies of scale at the sector-level rather than low elasticities of demand. Quantitatively, though, the sectorlevel economies of scale that we estimate in the pharmaceutical industry are about $25 \%$ smaller than those that Krugman's (1980) monopolistically competitive model predicts.

Finally, section 7 offers some concluding remarks.

\section{Related Literature}

The literature on the home-market effect is large and varied. As we explain below, the variation derives in part from the use of related, but distinct, definitions of "the" homemarket effect by different authors.

Whereas both Linder's (1961) and Krugman's (1980) original work emphasize the consequences of cross-country differences in demand for the pattern of trade, Helpman and Krugman (1985) focus instead on whether larger countries tend to specialize in sectors with larger economies of scale. ${ }^{3}$ Subsequent work by Davis (1998), Head et al. (2002), Holmes and Stevens (2005), and Behrens et al. (2009) provide additional conditions on the nature of trade costs as well as the number of goods and countries under which the latter pattern may or may not arise. Amiti (1998), in turn, studies whether larger countries should have a comparative advantage in sectors with higher trade costs. Motivated by the theoretical predictions of Helpman and Krugman (1985), Hanson and Xiang (2004) show that high-GDP countries tend to sell disproportionately more in sectors with larger transportation costs and lower elasticities of substitution, a measure of sector-level economies of scale under monopolistic competition. In related work, Feenstra, Markusen and Rose (2001) document that high-GDP countries tend to be net exporters of differentiated goods, which they also interpret as evidence of a home-market effect in such industries.

A number of more recent theoretical papers have extended the work of Krugman (1980) to study the implications of non-homothetic preferences for the pattern of trade and foreign direct investment; see Fajgelbaum, Grossman and Helpman $(2011,2015)$ and Matsuyama (2015). A key prediction of these models is that in the presence of economies of scale, rich countries that have larger demand for high-quality goods will tend to specialize in those goods. As a result, they will trade more with, or invest more in, other rich countries, as also emphasized by Linder (1961). While not strictly speaking about cross-country differences in demand-exogenous income differences are ultimately causing the pattern of trade--the underlying mechanism is the same as in Krugman (1980).

\footnotetext{
${ }^{3}$ Ethier (1982) discusses similar issues in a perfectly competitive model with external economies of scale.
} 
In line with the previous models, Caron, Fally and Fieler (2015) document that the sectors on which high-GDP countries spend more also tend to be the sectors in which high-GDP countries export more. Dingel (2015) also offer empirical evidence consistent with the previous mechanism using information about shipment prices from different U.S. cities and the income composition of neighboring cities.

Our analysis is most closely related to the early empirical work of Davis and Weinstein (1996) and later studies by Davis and Weinstein $(1999,2003)$, Lundback and Torstensson (1998), Head and Ries (2001), Trionfetti (2001), Weder (2003), Crozet and Trionfetti (2008), and Brulhart and Trionfetti (2009). Like ours, the aforementioned papers focus on the impact of differences in demand on the pattern of international specialization. In their review of the literature, Head and Mayer (2004) conclude that this type of empirical evidence on the home-market effect is highly mixed. ${ }^{4}$ While empirical specifications and data sources vary across studies, the previous papers all share one key characteristic: data on expenditure shares are used as a proxies for demand differences. As argued earlier, one non-trivial issue with such proxies is that differences in local supply conditions may also be affecting expenditure shares through their effect on local prices. This makes earlier tests of the home-market effect hard to interpret.

Compared to earlier work on the home-market effect, we view the approach in this paper as having both costs and benefits. Since the home-market effect emphasized by Linder (1961) and Krugman (1980) is about the causal effect of demand differences across countries, any test of this effect ultimately requires exogenous demand variation. While we have no silver bullet to deal with endogeneity issues, and we discuss those associated with our approach later in the paper, we believe that using (predicted) disease burdens as observable demand shifters rather than expenditure shares is a significant step forward.

The obvious drawback of our empirical strategy is that its scope is narrower: we focus on a single industry, although an important one. ${ }^{5}$ Another limitation of our dataset is that it does not allow us to distinguish between exports and foreign direct investment. We only observe total sales by firms headquartered in a particular country. Thus, the home-market effect that we identify may operate through both exports and foreign direct investment, not just exports, as emphasized in the previous literature. The previous observation notwithstanding, it is not clear that if the only choice was to study either ex-

\footnotetext{
${ }^{4}$ Given our focus on the pharmaceutical industry, it is worth nothing that Trionfetti's (2001) sector-level test is rejected for "Chemical Products."

${ }^{5}$ According to the statistics of the World Trade Organization, global exports in the pharmaceutical industry grew faster between 1995 and 2014 than in any other besides fuel, surpassing $\$ 500$ billion (or approximately three percent of global merchandise trade) by 2014. The pharmaceutical sector has also received considerable attention in recent trade agreements, particularly the Agreement on Trade-Related Aspects of Intellectual Property Rights (TRIPS) and the Trans-Pacific Partnership (TPP).
} 
ports or the sum of exports and sales by foreign affiliates, one should prefer the former to the latter. Indeed, the same economic forces are likely to be at play for both types of sales.

\section{Theory}

For expositional purposes, we first consider a world economy with perfect competition (Section 3.1) and develop a simple test of the home-market effect in this environment (Section 3.2). We then show that the previous test remains valid in a range of imperfectly competitive environments (Section 3.3).

\subsection{Basic Environment}

Demand Individuals consume drugs that target multiple diseases, indexed by $n$, as well as other goods, which we leave unspecified. Empirically, each disease $n$ will correspond to a broad disease class like "cardiovascular diseases." We assume that the aggregate consumption of drugs targeting disease $n$ in country $j$ can be expressed as

$$
D_{j}^{n}=\theta_{j}^{n} D\left(P_{j}^{n} / P_{j}\right) D_{j}
$$

where $P_{j}^{n}$ depends on the prices of drugs targeting disease $n$ in country $j$, as described below; $D_{j}$ and $P_{j}$ are endogenous country-specific demand shifters that are common to all drugs in country $j$; and $\theta_{j}^{n}$ is an exogenous disease-and-country-specific demand shifter, which we will later measure using data on disease burdens.

Within each disease category $n$, drugs may be purchased from different countries. Any of these countries may be producing different versions of the same molecule (e.g. generic versus non-generic), different molecules targeting the same narrow disease (e.g. angiotensin II receptor blockers and beta blockers, both treatments for high blood pressure, a risk factor for hypertensive heart disease), or different molecules targeting different diseases within the same broad category (e.g. drugs targeting hypertensive heart disease vs. coronary artery disease, within the broad category of cardiovascular diseases). The previous considerations suggest imperfect substitutability between drugs from different countries, which we capture through the following specification,

$$
d_{i j}^{n}=d\left(p_{i j}^{n} / P_{j}^{n}\right) D_{j}^{n},
$$

where $d_{i j}^{n}$ denotes country $j^{\prime}$ s consumption of varieties from country $i$ targeting disease

$n, p_{i j}^{n}$ denotes the consumer price for these varieties, and $P_{j}^{n}$ is implicitly defined by the 
solution to

$$
P_{j}^{n}=\sum p_{i j}^{n} d\left(p_{i j}^{n} / P_{j}^{n}\right)
$$

Given the level of aggregation in our empirical analysis, $p_{i j}^{n}$ should itself be interpreted as a price index, aggregating prices across all firms from country $i$ selling drugs targeting disease $n$ in country $j$. We will make this aggregation explicit in Sections 3.3 and 6.1. ${ }^{6}$

Supply Perfectly competitive firms produce up to the point at which drug prices are equal to marginal costs. For each disease $n$ and country $i$, this leads to a supply curve,

$$
s_{i}^{n}=\eta_{i}^{n} s\left(p_{i}^{n}\right),
$$

where $p_{i}^{n}$ denotes the producer price of drugs targeting disease $n$ in country $i$ and $\eta_{i}^{n}$ is a disease-and-country specific supply shifter, which may capture both technological and policy differences. Depending on whether there are external economies of scale or not, $s(\cdot)$ may be upward- or downward-sloping. Trade is subject to iceberg frictions. To sell one unit of a given drug to country $j \neq i$, firms from country $i$ must ship $\tau_{i j}^{n} \geq 1$ units. $^{7}$ Without loss of generality, we set $\tau_{i i}^{n}=1$ for all $i$ and $n$. Non-arbitrage implies

$$
p_{i j}^{n}=\tau_{i j}^{n} p_{i}^{n}
$$

Equilibrium Supply equals demand for each drug,

$$
s_{i}^{n}=\sum_{j} \tau_{i j}^{n} d_{i j}^{n}
$$

\footnotetext{
${ }^{6}$ For the purposes of testing the home-market effect, we do not need the previous demand functions to be consistent with the behavior of a representative agent in country $j$, an assumption that may be particularly strong in a sector where demand involves physicians, pharmacists, insurers, and patients. We note, however, that equations (1)-(3) are consistent with the common assumption of nested CES utility functions, which corresponds to the special case where $D(\cdot)$ and $d(\cdot)$ are power functions.

${ }^{7}$ Though we abstract from multinational production in our baseline model, equations (4) and (5) would still hold in a world economy with multinational activities à la Ramondo and Rodríguez-Clare (2013). In such an environment, $\tau_{i j}^{n}$ would simply correspond to the minimum cost of accessing country $j$ from country $i$, either through exports or foreign direct investment; see Appendix A. Note also that while transport costs and tariffs are low in the pharmaceutical industry, drug sales exhibit significant home-bias. This is partly due to local regulations that act as non-tariff barriers; see Thomas (1994). For example, governments may favor domestic firms in granting approval or when negotiating prices. Iceberg trade costs in our baseline model aim to capture all the frictions involved when selling pharmaceuticals in foreign markets that appear to persist, notwithstanding the adoption of free trade agreements and international efforts to harmonize regulations.
} 


\subsection{A Simple Test of the Home-Market Effect}

The home-market effect is the general idea that, everything else being equal, countries tend to sell more abroad in sectors for which they have larger domestic markets. Here, we operationalize this idea in the context of a log-linearized version of our model.

Log-linear Specification Let $x_{i j}^{n} \equiv p_{i j}^{n} d_{i j}^{n}$ denote the equilibrium sales of drugs targeting disease $n$ by firms from country $i$ in country $j \neq i$. Around a symmetric equilibrium with trade costs, $\tau \geq 1$, and common demand and supply shocks across countries and diseases, we can express bilateral sales, up to a first-order approximation, as

$$
\ln x_{i j}^{n}=\delta_{i j}+\delta^{n}+\beta_{M} \ln \theta_{j}^{n}+\beta_{X} \ln \theta_{i}^{n}+\varepsilon_{i j}^{n}
$$

where $\delta_{i j}$ is an origin-times-destination-specific term that captures systematic determinants of bilateral trade flows such as physical distance or whether countries $i$ and $j$ share the same language; $\delta^{n}$ is a disease-specific term that captures worldwide variation in demand and supply conditions across drugs targeting different diseases; $\beta_{M}$ is the elasticity of trade flows with respect to demand shocks in the importing country; $\beta_{X}$ is the elasticity of trade flows with respect to demand shocks the exporting country $j$; and $\varepsilon_{i j}^{n}$ is a residual that captures idiosyncratic variation in trade costs and supply conditions.

The mapping between the previous elasticities and variables and the structural parameters of Section 3.1 can be found in Appendix B. The economic interpretation of $\beta_{M}$ and $\beta_{X}$-the two elasticities that we estimate below and that are central to our analysis-is discussed in detail below. One important feature of equation (7), from the perspective of the empirical strategy that we develop, is that the term $\varepsilon_{i j}^{n}$ depends on the supply shifter at home, $\eta_{i}^{n}$, and trade costs in all countries around the world, $\left\{\tau_{i j}^{n}\right\}$, but not on demand shifters, $\left\{\theta_{i}^{n}\right\}$. Around a symmetric equilibrium, taste shifters in countries $l \neq i, j$ enter only through the disease fixed-effect, $\delta^{n}$. Hence, the log-linear derivation here suggests that one need not impose any restriction on the spatial correlation of demand shocks across countries in order to estimate $\beta_{M}$ and $\beta_{X}$ via equation (7), though we do allow for the possibility of empirical departures from this in Section 5.2.

Starting from equation (7), we can then express country $i^{\prime}$ s total exports, $X_{i}^{n} \equiv \sum_{j \neq i} x_{i j^{\prime}}^{n}$ 
and total imports, $M_{i}^{n} \equiv \sum_{j \neq i} x_{j i}^{n}$, of drugs targeting disease $n$ as

$$
\begin{aligned}
& X_{i}^{n}=\exp \left(\delta^{n}\right) \times\left(\sum_{j \neq i}\left(\theta_{j}^{n}\right)^{\beta_{M}} \exp \left(\delta_{i j}+\varepsilon_{i j}^{n}\right)\right) \times\left(\theta_{i}^{n}\right)^{\beta_{X}}, \\
& M_{i}^{n}=\exp \left(\delta^{n}\right) \times\left(\sum_{j \neq i}\left(\theta_{j}^{n}\right)^{\beta_{X}} \exp \left(\delta_{j i}+\varepsilon_{j i}^{n}\right)\right) \times\left(\theta_{i}^{n}\right)^{\beta_{M}} .
\end{aligned}
$$

According to equation (8), after taking into account differences in world exports across diseases, as captured by $\exp \left(\delta^{n}\right)$, and differences in the "proximity" to large buyers, as captured by $\sum_{j \neq i}\left(\theta_{j}^{n}\right)^{\beta_{M}} \exp \left(\delta_{i j}+\varepsilon_{i j}^{n}\right)$, a country tends to export more of the goods for which it has larger domestic demand if and only if $\beta_{X}>0$. And according to equation (9), after also taking into account differences in the "proximity" to large sellers, $\sum_{j \neq i}\left(\theta_{j}^{n}\right)^{\beta_{X}} \exp \left(\delta_{j i}+\varepsilon_{j i}^{n}\right)$, a country tends to be a net exporter of the goods for which it has a larger domestic market if and only if $\beta_{X}>\beta_{M} .{ }^{8}$ These two observations motivate the following definition.

Definition. A given cross-section of bilateral sales $\left\{x_{i j}^{n}\right\}$ satisfies the weak home-market effect if $\beta_{X}>0$ and the strong home-market effect if $\beta_{X}>\beta_{M}$.

Our definition, while natural in the context of our model, differs from earlier tests of the home-market effect. Three features of our definition are worth emphasizing.

First, and most importantly, it focuses on elasticities with respect to demand shocks, not expenditure shares. If preferences across sectors are Cobb-Douglas, the two elasticities are equivalent. Away from this empirically knife-edge case, they are not. Assuming that observable demand shocks are available, a case that we make in Section 4, using these shocks alleviates concerns about "false positives" - that is, positive correlations between exports and expenditure shares driven by unobserved supply shocks that are positively correlated with both exports and expenditure shares, absent any variation in demand.

Second, our definition focuses on elasticities with respect to a country's own demand, that is, its home market, not its overall market access. As discussed above, the variation in demand from neighboring countries is taken into account in our analysis-for example, in equation (8) via the terms $\delta^{n}$ and $\sum_{j \neq i}\left(\theta_{j}^{n}\right)^{\beta_{M}} \exp \left(\delta_{i j}+\varepsilon_{i j}^{n}\right)$. However, under our definition, we only conclude that a home-market effect arises if, conditional on the same level of demand in neighboring countries, countries with higher domestic demand have relatively higher exports. This addresses concerns about a positive test of the home-market effect arising because of a mechanical relationship between exports and foreign demand shocks.

\footnotetext{
${ }^{8}$ Recall that if $X / M$ is increasing in $\theta$, then $X-M=M(X / M-1)$ must be positive for $\theta$ high enough and negative otherwise.
} 
Third, our definition introduces the distinction between the weak home-market effect, which focuses on gross exports, and the strong home-market effect, which focuses on net exports. As we argue next, the weak test, which is unique to our paper, provides a direct way to identify departures from the predictions of neoclassical trade models. The strong test merely puts tighter bounds on the magnitude of these departures, if any.

Economic Interpretation. The economic forces that give rise to weak and strong homemarket effects are best illustrated in a world economy comprising a large number of small open economies in the sense that each country is too small to affect the price of foreign varieties, but large enough to affect the price of its own varieties, as in Gali and Monacelli (2005). In this case, the two elasticities, $\beta_{X}$ and $\beta_{M}$, simplify into

$$
\begin{aligned}
& \beta_{X}=\frac{\lambda\left(1-\epsilon^{x}\right)}{\epsilon^{s}+\epsilon^{w}}, \\
& \beta_{M}=1+\frac{\lambda^{2}\left(1-\epsilon^{d}\right)\left(\epsilon^{x}-\epsilon^{D}\right)}{\left(1-\lambda \epsilon^{d}-(1-\lambda) \epsilon^{x}\right)\left(\epsilon^{\mathcal{S}}+\epsilon^{w}\right)},
\end{aligned}
$$

where $\lambda>0$ is the share of expenditure, as well as revenue, on domestic drugs in the symmetric equilibrium; $\epsilon^{d}>0$ and $\epsilon^{x}>0$ are the lower-level elasticities of demand for domestic and foreign varieties, respectively; $\epsilon^{D}>0$ is the upper-level elasticity of demand; $\epsilon^{w} \equiv \lambda \epsilon^{d}+(1-\lambda) \epsilon^{x}-\lambda^{2}\left(1-\epsilon^{d}\right)\left(\epsilon^{d}-\epsilon^{D}\right) /\left(1-\lambda \epsilon^{d}-(1-\lambda) \epsilon^{x}\right)>0$ is the elasticity of world demand; and $\epsilon^{s}$ is the elasticity of supply, which may be positive or negative, depending on whether there are economies of scale. ${ }^{9}$

Suppose that $\epsilon^{x}>1$ so that countries with lower prices tend to have higher market shares abroad, which will be the empirically relevant case. Then, according to equation (10), there can only be a weak home-market effect in the presence of economies of scale,

$$
\epsilon^{s}<-\epsilon^{w}<0
$$

In a neoclassical environment, an increase in domestic demand across sectors, i.e. a positive shift in $\theta$, raises world demand, $d$, and in turn, producer prices, $p$, as depicted in Figure 1a. If the price elasticity of exports, $\epsilon^{x}$, is strictly greater than one, this necessarily lowers the value of exports, $X$, as depicted in Figure $1 b$. By lowering the price of goods with larger domestic markets, economies of scale can instead create a positive relationship between exports and domestic demand, as described in Figures 2a and 2b.

\footnotetext{
${ }^{9}$ Formally, we obtain the small open economy limit by taking the number of countries in the world economy to infinity and adjusting trade costs, $\tau$, to leave the expenditure share on a country's own good, $\lambda$, at a constant and strictly positive level.
} 


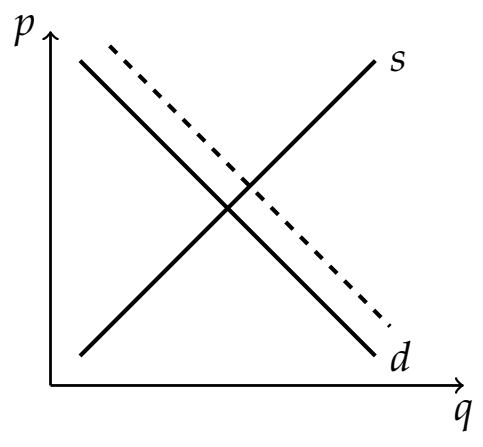

(a) Price and quantity.

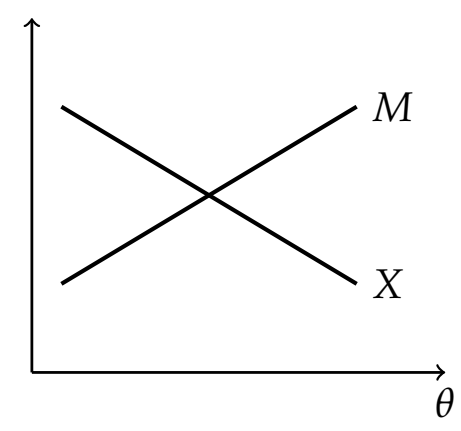

(b) Exports and imports.

Figure 1: Neoclassical Benchmark.

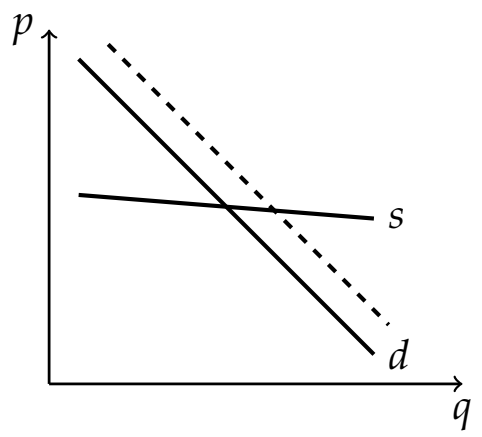

(a) Price and quantity.

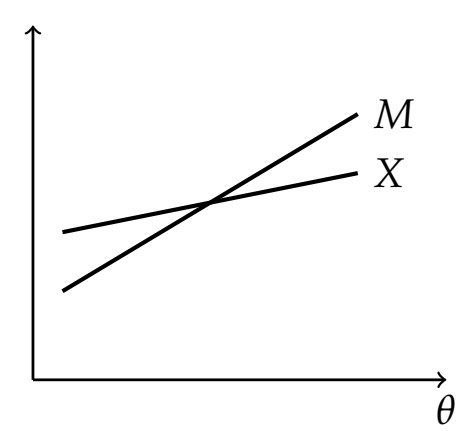

(b) Exports and imports.

Figure 2: Weak home-market effect.

Suppose, in addition, that $\epsilon^{d}>1$ and $\epsilon^{x} \geq \epsilon^{D}$. The second inequality is another mild restriction that requires, for example, French and American drugs targeting cardiovascular diseases to be closer substitutes than drugs targeting cardiovascular and skin diseases. Under this restriction, equations (10) and (11) imply that a strong home-market effect arises if economies of scale are strong enough to dominate the direct effect of domestic demand on imports, namely if

$$
-\epsilon^{w}-\lambda\left(\epsilon^{x}-1+\lambda\left(1-\epsilon^{d}\right)\left(\epsilon^{x}-\epsilon^{D}\right) /\left(1-\lambda \epsilon^{d}-(1-\lambda) \epsilon^{x}\right)\right)<\epsilon^{\mathcal{S}}<-\epsilon^{w} .
$$

This situation is depicted in Figure 3. 


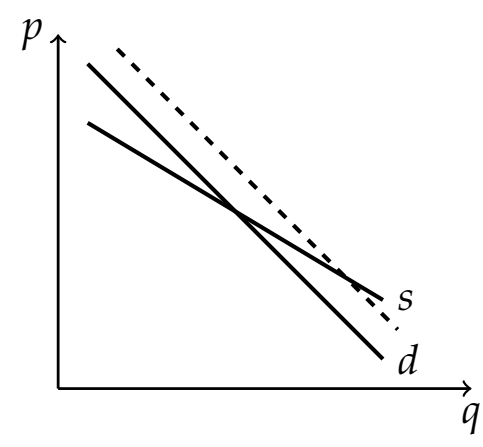

(a) Price and quantity.

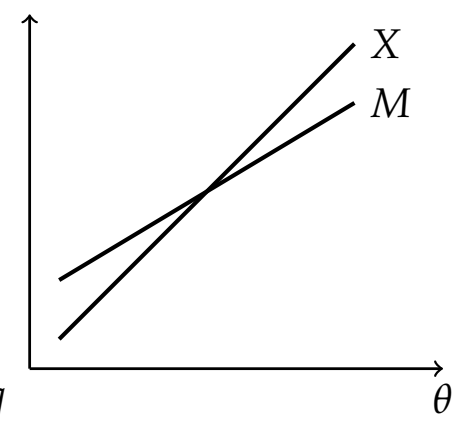

(b) Exports and imports.

Figure 3: Strong home-market effect.

\subsection{Robustness}

We have conducted our theoretical analysis in a stylized model with perfect competition. Our empirical analysis will focus on the global pharmaceutical industry, a complex sector in which patents and other barriers to entry provide an important source of market power. A natural question therefore is the extent to which our simple test, and its interpretation, may carry over to this industry. To shed light on this issue, we provide three examples that illustrate how more complex economic environments, without perfect competition, may reduce to exactly the same equilibrium conditions as in Section 3.1. This establishes that the simple test presented in Section 3.2 remains valid in a range of imperfectly competitive environments. ${ }^{10}$ For expositional purposes, we only sketch alternative market structures and summarize their main implications. Details can be found in Appendix C.

Monopolistic Competition Consider first an economy where what we have referred to as "country i's variety" in Section 3.1 is itself a composite of multiple differentiated varieties, each produced by monopolistically competitive firms, as in Krugman (1980).

Formally, suppose that country $j$ 's consumption of drugs targeting disease $n$ produced by a firm $\omega$ from country $i$ is given by

$$
d_{i j}^{n}(\omega)=\left(p_{i j}^{n}(\omega) / p_{i j}^{n}\right)^{-\sigma} d_{i j}^{n}
$$

where $p_{i j}^{n}=\left(\int\left(p_{i j}^{n}(\omega)\right)^{1-\sigma)} d \omega\right)^{1 /(1-\sigma)}$ is the Dixit-Stiglitz price index and $\sigma>1$ is the elasticity of substitution between country $i$ 's varieties. All other assumptions on the struc-

\footnotetext{
${ }^{10}$ Thus, while the scope of our empirical analysis in Section 5 concerns a single sector with many idiosyncratic features-its cost structure, its reliance on intellectual property, and the role of regulation-the test that we have introduced in the previous subsection could be applied to many others.
} 
ture of demand are the same as in Section 3.1. On the supply side, each firm must now pay an overhead fixed cost, $f_{i}^{n}>0$, in order to produce. Once this fixed cost has been paid, firms have a constant marginal cost, $c_{i}^{n}>0$. All firms maximize profits taking their residual demand curves as given and enter up to the point where profits net of the overhead fixed cost are equal to zero.

At the industry-level, the previous assumptions lead to a supply curve similar to (4). Let us define Home's aggregate supply of drug $n$ as the following quantity index,

$$
s_{i}^{n}=\left(\int\left(s_{i}^{n}(\omega)\right)^{(\sigma-1) / \sigma} d \omega\right)^{\sigma /(\sigma-1)},
$$

where $s_{i}^{n}(\omega) \equiv \sum_{j} \tau_{i j}^{n} d_{i j}^{n}(\omega)$ is the total quantity supplied by firm $\omega$, regardless of whether it is ultimately sold domestically or exported. Since demand is iso-elastic, monopolistically competitive firms charge constant markups, $\mu \equiv \sigma /(\sigma-1)$, over marginal costs. Together with free entry, this leads to

$$
\begin{aligned}
s_{i}^{n} & =\left(N_{i}^{n}\right)^{\sigma /(\sigma-1)} f_{i}^{n} /\left((\mu-1) c_{i}^{n}\right), \\
p_{i}^{n} & =\left(N_{i}^{n}\right)^{1 /(1-\sigma)} \mu c_{i}^{n} .
\end{aligned}
$$

where we let $p_{i}^{n} \equiv p_{i i}^{n}$ denote the price index associated with country $i^{\prime}$ s varieties before trade costs have been incurred and we let $N_{i}^{n}$ denote the measure of firms producing drugs targeting disease $n$ in country $i$. The two previous expressions provide a parametric representation of the sector-level supply curve, with the number of firms $N_{i}^{n}$ acting as a parameter. In this case, one can eliminate $N_{i}^{n}$ to express the supply curve explicitly as

$$
s_{i}^{n}=\eta_{i}^{n}\left(p_{i}^{n}\right)^{-\sigma},
$$

with $\eta_{i}^{n} \equiv f_{i}^{n}\left(c_{i}^{n}\right)^{(\sigma-1)} \sigma^{\sigma}(\sigma-1)^{(1-\sigma)}$. This is the counterpart of the supply equation (4). Finally, since firms charge the same markup $\mu$ in all markets, equation (5) must hold for the price indices, $p_{i j}^{n}$, of country $i$ 's varieties of $\operatorname{drug} n$ in any importing country $j$.

At this point, we have established that equations (1)-(5) continue to hold. By construction of our quantity index, equation (6) must hold as well, as shown in Appendix C. This implies that our simple test remains valid under monopolistic competition. The only distinction between the perfectly competitive model of Section 3.1 and the present one is that monopolistic competition requires sector-level supply curves to be downwardsloping, with an elasticity equal to the opposite of the elasticity of substitution between domestic varieties,

$$
\epsilon^{s}=-\sigma \text {. }
$$


It is worth pointing out that the magnitude of the overhead fixed cost, $f_{i}^{n}$, is irrelevant for the shape of $s$ and, in turn, irrelevant for the existence of a home-market effect. Though pharmaceutical firms are well-known for having large expenditures on research and development relative to the cost of manufacturing a drug, it does not follow that homemarket effects should be particularly strong in that industry. The economic variable of interest for home-market effects is the magnitude of industry-level returns to scale-determined by $\sigma$ under monopolistic competition-not firm-level returns to scale.

Note also that in the special case considered by Krugman (1980) - with upper-level Cobb-Douglas utility, $\epsilon^{D}=1$, and lower-level CES utility, $\epsilon^{x}=\epsilon^{d}=\sigma$-the homemarket effect is always strong for a small open economy. Indeed, under these parametric restrictions, inequality (12) reduces to

$$
-\sigma-\lambda(\sigma-1)<-\sigma<-\sigma+\lambda^{2}(\sigma-1)
$$

which must hold for any $\lambda>0$ and $\sigma>1$. In this important benchmark case, whether the test of the home-market effect introduced in Section 3.2 is positive or negative is therefore independent of the particular symmetric equilibrium that we are log-linearizing around.

Bertrand Oligopoly Consider the same basic environment as in the previous example, but with a finite number of firms, $N_{i}^{n}$, that compete à la Bertrand in each sector. To simplify the analysis, we further assume that $\epsilon^{D}=\epsilon^{x}=\epsilon^{d}$ and that there is an arbitrarily large number of diseases so that firms charge the same markup in all markets. ${ }^{11}$ All other assumptions are unchanged.

In equilibrium, firms still maximize their profits taking their residual demand curves as given, albeit internalizing the effect of their decisions on the domestic price index associated with each disease. This leads to markups that now vary with the number of firms $N_{i}^{n}$. Formally, one can show that country $i$ 's aggregate supply of drug $n$ and its price index now satisfy

$$
\begin{aligned}
s_{i}^{n} & =\left(N_{i}^{n}\right)^{\sigma /(\sigma-1)} f_{i}^{n} /\left(\left(\mu\left(N_{i}^{n}\right)-1\right) c_{i}^{n}\right), \\
p_{i}^{n} & =\left(N_{i}^{n}\right)^{1 /(1-\sigma)} \mu\left(N_{i}^{n}\right) c_{i}^{n},
\end{aligned}
$$

with $\mu\left(N_{i}^{n}\right) \equiv \frac{\left(\left(1-1 / N_{i}^{n}\right) \sigma+\epsilon^{d} / N_{i}^{n}\right)}{\left(1-1 / N_{i}^{n}\right) \sigma+\epsilon^{d} / N_{i}^{n}-1}$ the firms' markup under Bertrand competition. Though one can no longer solve explicitly for $s_{i}^{n}$ as a function of $p_{i}^{n}$, the two previous expressions

\footnotetext{
${ }^{11}$ In practice, pricing-to-market may be difficult to sustain in the pharmaceutical industry because of parallel trade, as in the case of the European Union, or because of the use of "international reference pricing" more generally; see Scott Morton and Kyle (2012) for further discussion.
} 
still provide a parametric representation of the sector-level supply curve. Since equations (1), (2), and (5) remain unchanged, the existence of such a curve is all we need to apply our simple test.

Locally, the price elasticity of supply is now given by

$$
\epsilon^{\mathcal{S}}=-\sigma \times \frac{(\mu-1)^{2}+(1-1 / \sigma)(d \ln \mu / d \ln N)}{(\mu-1)^{2}(1-(\sigma-1)(d \ln \mu / d \ln N))}
$$

Compared to monopolistic competition with constant markups, where $d \ln \mu / d \ln N=0$, the supply elasticity is lower in absolute value, $\left|\epsilon^{s}\right|<\sigma$, whenever markups are decreasing with the number of firms, $d \ln \mu / d \ln N<0$. This is what happens for $\sigma>\epsilon^{d}$. In this case, the larger aggregate output in an industry is, the more firms there are, the lower the markups that they charge, and hence the lower the price that firms are willing to accept to produce a given aggregate quantity. At the sector-level, pro-competitive effects act as an additional source of increasing returns.

Monopoly To conclude, let us consider an economy where countries only produce a single variety of each drug, but unlike in our basic environment, this variety is produced by a monopolist that can invest in R\&D, as in Krugman (1984). We follow the same strategy as in the previous example and assume that $\epsilon^{D}=\epsilon^{x}=\epsilon^{d}$ and that there is an arbitrarily large number of drugs so that firms charge the same markup in all markets.

For each disease $n$, the domestic monopolist in country $i$ takes the residual demand curve in each market as given when simultaneously choosing its prices, $p_{i j}^{n}$, and its unit cost of production, $c_{i}^{n}$, in order to maximize its profits,

$$
\pi_{i}^{n}=\sum_{j}\left(p_{i j}^{n}-\tau_{i j}^{n} c_{i j}^{n}\right) d\left(p_{i j}^{n} / P_{j}^{n}\right) D\left(P_{j}^{n} /\left(\theta_{j}^{n} P_{j}\right)\right) D_{j}-\eta_{i}^{n} f\left(c_{i}^{n}\right),
$$

where $\eta_{i}^{n} f\left(c_{i}^{n}\right)$ denotes the amount of R\&D required to have unit cost, $c_{i}^{n}$, which we assume to be strictly decreasing and convex. The first-order conditions associated with this maximization problem imply the following version of the supply equation (4),

$$
s_{i}^{n}=-\eta_{i}^{n} f^{\prime}\left(\left(\epsilon^{d}-1\right) p_{i}^{n} / \epsilon^{d}\right) .
$$

Under the assumption that $f(\cdot)$ is convex, drug-level supply curves are necessarily downwardslopping with local elasticity now given by

$$
\epsilon^{s}=d \ln \left(-f^{\prime}\right) / d \ln c
$$


The critical feature of the present model is that the marginal benefit of $R \& D$ is increasing with total output, which creates a negative relationship between output and prices.

In the four market structures that we have considered-perfect competition, monopolistic competition, Bertrand competition, and a single monopoly - the nature of economies of scale at the sector-level is very different. Here, it depends on the elasticity of the marginal returns to R\&D; previously, it derived from Marshallian externalities, love of variety, or pro-competitive effects. Nevertheless, equations (1)-(6) always hold. So, the simple economics of the home-market effect described in Section 3.2 remains valid. This motivates an empirical strategy that is agnostic about such considerations, to which we now turn.

\section{Data}

Our analysis of the home-market effect rests on the correlation between a country's pattern of sales across drugs in the pharmaceutical sector and its pattern of exogenouslygiven demand across those drugs. We therefore draw on a linkage between two datasets: one that documents sales by country at the drug level, which we convert to a dataset of bilateral sales as detailed below, and one that describes the demographically-driven burden of each disease in each country. In both cases we use data from 2012: one cross-section of data suffices for testing the home-market effect since its prediction is cross-sectional in nature.

\subsection{Pharmaceutical Sales}

In order to construct bilateral data on pharmaceutical sales, $\left\{x_{i j}^{n}\right\}$, we draw on the MIDAS dataset produced by the firm IMS Health. IMS is a market research firm that sells MIDAS and other data products to firms in the pharmaceutical and health care industries. By auditing retail pharmacies, hospitals, and other sales channels, the raw MIDAS data record quarterly revenues and quantities by country at the "package" level, e.g. sales of a bottle of thirty 10mg tablets of the cholesterol-lowering drug Lipitor (atorvastatin). The data record unit sales and revenues (in local currency units), for both private and public purchasers.

Our version of the MIDAS dataset covers sales in 56 destination countries. ${ }^{12}$ Given the comprehensive nature of the dataset, the vast majority of high revenue drugs globally-over 20,000 unique molecules or combinations of molecules, both brand-name and

\footnotetext{
${ }^{12}$ The most recent versions of the MIDAS dataset cover more than 70 countries.
} 
Table 1: Top 10 countries in terms of sales

\begin{tabular}{|c|c|c|c|}
\hline & $\begin{array}{c}\text { Share of } \\
\text { world sales (\%) }\end{array}$ & $\begin{array}{l}\text { Share of world } \\
\text { expenditures }(\%)\end{array}$ & $\begin{array}{c}\text { Number of firms } \\
\text { headquartered }\end{array}$ \\
\hline Country & (1) & (2) & (3) \\
\hline USA & 36.67 & 42.10 & 361 \\
\hline Switzerland & 13.14 & 0.61 & 35 \\
\hline Japan & 11.62 & 12.67 & 53 \\
\hline United Kingdom & 10.69 & 2.67 & 79 \\
\hline Germany & 6.75 & 4.67 & 89 \\
\hline France & 6.52 & 4.34 & 59 \\
\hline India & 2.28 & 1.61 & 292 \\
\hline China (Mainland) & 2.18 & 3.74 & 524 \\
\hline Canada & 1.40 & 2.57 & 48 \\
\hline Italy & 1.35 & 3.36 & 63 \\
\hline
\end{tabular}

generic-are included. Our sample includes sales by roughly 2,650 firms. We observe the name of the firm selling each drug in our dataset and have used this name to hand-match each firm to the country in which it is headquartered. ${ }^{13}$ We refer to this country as the origin country. Given this mapping of firms to origin countries, we then use the MIDAS data on sales (for each drug) by firm in each destination country to measure bilateral sales, from origin country to destination country, for each drug. ${ }^{14}$ We reiterate that the resulting bilateral sales data do not differentiate between exports and FDI-driven sales; they comprise the sum of all channels through which a firm in origin country $i$ sells its product to consumers in destination country $j$. In addition, our bilateral sales data do not capture licensing. For example, if Gilead licenses a treatment to several Indian pharmaceutical makers who then sell in other markets, those sales are attributed to the licensees rather than to Gilead.

The ten largest firms in our dataset in terms of sales (with origin country in parentheses) are, in descending order, Novartis (Switzerland), Pfizer (US), Merck \& Co. (US), Sanofi-Aventis (France), Roche (Switzerland), AstraZeneca (UK), GlaxoSmithKline (UK), Johnson \& Johnson (US), Eli Lilly \& Co. (US), and Abbvie (US, a spin-off of Abbott Laboratories). ${ }^{15}$ While these top ten firms are headquartered in just four countries, firms in

\footnotetext{
${ }^{13}$ We have been able to ascertain the headquarters location for firms that cover $94.5 \%$ of total 2012 sales in the MIDAS dataset.

${ }^{14}$ The baseline analysis of Section 5 uses a "square" sample in which origin countries are only included if they also appear as destination countries (that is, they are one of the 56 destination markets in the MIDAS dataset). A specification check in Table 4 confirms that this has little bearing on our results.

${ }^{15}$ All comparisons across local currency units in this section use average 2012 exchange rates from the World Bank's World Development Indicators database. Due to the presence of destination fixed-effects, the
} 
our dataset are headquartered in a total of 55 (out of a possible 56) different origin countries. Table 1 reports the distribution of global sales for the ten largest countries in terms of share of world sales, along with the number of firms that are headquartered in each of those countries. There is a clear skewness in both of these variables, so we conduct our tests of the home-market effect in a wide range of subsamples designed to explore potential heterogeneity across large and small countries, as well as countries (such as India and China) where the large number of headquartered firms reflects a relatively large share of generic drug producers.

IMS uses a standard industry classification known as ATC codes, from the Anatomical Therapeutic Chemical Classification System to classify molecules into approximately 600 different therapeutic classes based on the main disease the drug is designed to treat. To link back to the example in our introduction, the ATC code "A02B" corresponds to "drugs for peptic ulcer and gastro-esophageal reflux disease."

The resulting dataset can be reshaped to describe, within each therapeutic class, the bilateral sales between any origin country and any of 56 destination countries in 2012 .

\subsection{Disease Burden}

We isolate a plausibly exogenous source of demand-side variation for each drug, in each country, by isolating the apparent extent to which drugs have a demographic bias in their relevance, as well as the extent to which countries differ in the demographic composition of their populations. This is the spatial analog of the identification strategy in Acemoglu and Linn (2004), who use changes in the age distribution of the United States over time to estimate the relationship between market size and innovation in the pharmaceutical industry.

To construct this demand shifter, we draw on two datasets. The first, the World Health Organization (WHO)'s Global Burden of Disease (GBD) dataset, measures the burden of each disease, based on $60 \mathrm{WHO}$ disease codes, in each country and year (where, again, we focus on 2012). Although there may be local variation in the collection of vital statistics that underpin these measures, the WHO ensures that these data are valid for crosscountry and cross-disease comparisons. Importantly, these country-year-disease measures of burden are further broken down into six different demographic groups: three age groups (0-14, 15-59 and 60+) for each gender. The provided disease burden measure on which we draw is the number of lost disability adjusted life-years (DALYs)—combining

home-market effect tests in Section 5 and the parameter estimates in Section 6 do not require a conversion across local currency units. 


\begin{tabular}{|c|c|c|c|}
\hline & $\begin{array}{c}\text { Share of } \\
\text { world } \\
\text { sales (\%) }\end{array}$ & $\begin{array}{c}\text { Number of } \\
\text { origin } \\
\text { countries }\end{array}$ & $\begin{array}{c}\text { Average } \\
\text { Herfindahl } \\
\text { index across } \\
\text { destinations }\end{array}$ \\
\hline Disease class (WHO system) & $(1)$ & $(2)$ & (3) \\
\hline Other infectious diseases & 8.62 & 55 & 0.08 \\
\hline Hypertensive heart disease & 6.56 & 55 & 0.10 \\
\hline Other cardiovascular diseases & 6.30 & 55 & 0.13 \\
\hline Ischaemic heart disease & 5.99 & 54 & 0.14 \\
\hline Other neoplasms & 5.80 & 52 & 0.12 \\
\hline Diabetes mellitus & 4.75 & 54 & 0.15 \\
\hline Rheumatoid arthritis & 4.55 & 49 & 0.23 \\
\hline Other genitourinary system diseases & 3.97 & 51 & 0.14 \\
\hline Obstructive pulmonary disease & 3.50 & 49 & 0.27 \\
\hline Schizophrenia & 3.26 & 51 & 0.17 \\
\hline
\end{tabular}

data on both the mortality and morbidity — caused by each disease. We have hand-coded a linkage from each of the 600 therapeutic classes in IMS MIDAS to its corresponding WHO disease code. For example, the ATC code "A02B" for "drugs for peptic ulcer and gastro-esophageal reflux disease" is linked to the WHO code for "peptic ulcer disease."16 Each of the $60 \mathrm{WHO}$ codes is the empirical counterpart of a disease $n$ in the model of Section 3.

Table 2 describes the top 10 diseases (broken down by WHO codes) in terms of global sales of their corresponding drugs in the MIDAS dataset. For each disease, there are many origin countries participating in the sale of drugs treating that disease. As illustrated in the last column, the typical destination country in our data is served by an extremely unconcentrated set of firms, even within each disease class.

The second input into the construction of our demand shifter is the population of each country in each of the six demographic groups in 2012. We obtain this data from the US Census Bureau's International Database.

Using the data described above, we exploit the twin facts that disease burdens vary by demographic groups, and that countries vary in their demographic composition, to construct a "predicted disease burden", for disease $n$ in country $i$ in year 2012 as:

\footnotetext{
${ }^{16}$ Around $89 \%$ of our ATC4 codes were linked to WHO GBD codes. The main reason for non-matches is that certain ATC4 codes are too broad to be matched to a single GBD disease code.
} 


$$
(P D B)_{i}^{n}=\sum_{a, g}\left[\text { population }_{i a g} \times\left(\frac{\sum_{j \neq i}{\text { disease } \text { burden }_{j a g}^{n}}_{\sum_{j \neq i} \text { population }_{j a g}}}{\sum}\right)\right] .
$$

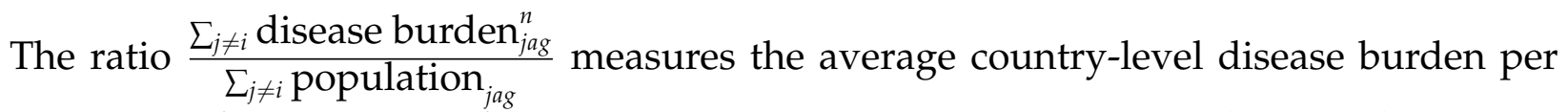
population from disease $n$ for gender $g$ and age group $a$ in 2012, calculated excluding the country of interest (that is, summing over all countries $j$ except for country $i$ ). This ratio is then weighted by the population for that gender $g$ and age group $a$, and summed across age and gender groups, for a given country $i$ in 2012.

\section{Testing for the Home-Market Effect}

\subsection{Baseline Results}

To test whether bilateral sales in the pharmaceutical industry satisfy the weak and strong home-market effects, we use $(P D B)_{i}^{n}$ as an empirical proxy for the demand-shifter $\theta_{i}^{n}$ in equation (1). That is, we assume that, up to a first-order approximation,

$$
\ln \theta_{i}^{n}=\gamma \ln (P D B)_{i}^{n}+\gamma_{i}^{n}
$$

where $\gamma$ is strictly positive and $\gamma_{i}^{n}$ is an error term that captures other determinants of the demand-shifter $\theta_{i}^{n}$ for drugs targeting disease $n$ in country $i$ that is uncorrelated with $(P D B)_{i}^{n}$. Our results in Table 3 below demonstrate that this proxy is a strong predictor of expenditure. And Table E.1 in Appendix E establishes that the variable $(P D B)_{i}^{n}$ is also a strong predictor of the actual burden that any country $i$ is likely to suffer from in disease $n$. That is, the simple demographic predictor of disease burden in equation (14) is a useful empirical proxy for $\theta_{i}^{n}$, despite the myriad other reasons for countries to differ in their demand for drugs targeting any particular disease.

Combining equations (7) and (15), we obtain our baseline estimating equation,

$$
\ln x_{i j}^{n}=\delta_{i j}+\delta^{n}+\tilde{\beta}_{M} \ln (P D B)_{j}^{n}+\tilde{\beta}_{X} \ln (P D B)_{i}^{n}+\tilde{\varepsilon}_{i j}^{n}
$$

with $\tilde{\beta}_{M} \equiv \gamma \beta_{M}, \tilde{\beta}_{X} \equiv \gamma \beta_{X}$, with $\delta_{i j}$ and $\delta^{n}$ represented by origin-destination and disease fixed-effects respectively, and with the error term given by $\tilde{\varepsilon}_{i j}^{n} \equiv \varepsilon_{i j}^{n}+\gamma_{i}^{n}$. Under the assumption that $\gamma>0$, a positive test of the weak home-market effect therefore corresponds to $\tilde{\beta}_{X}>0$, whereas a positive test of the strong home-market effect corresponds to $\tilde{\beta}_{X}>\tilde{\beta}_{M}$. And under the assumption that $\ln (P D B)_{i}^{n}$ is a pure demand-shifter-such 
that it is uncorrelated with the supply shifter $\eta_{i}^{n}$ and hence the error $\tilde{\varepsilon}_{i j}^{n}$-both $\tilde{\beta}_{X}$ and $\tilde{\beta}_{M}$ can be estimated using OLS, as we do below. ${ }^{17}$

Several details of the estimation procedure used in this section are important to note. First, we estimate equation (16) on a sample of $i j$ observations for which $i \neq j$, in line with the derivation of equation (7). This ensures that the trivial correlation between home's demand shifter and sales from home to itself does not enter the analysis (though in Table 4 we report the extent to which incorporating this variation changes our findings). Second, in our baseline estimates we drop observations for which $x_{i j}^{n}=0$, but we return this aspect of the variation in Table 8. And finally, because the predicted disease burden regressors vary at the origin and destination levels (but not at the bilateral level) we take a conservative approach to inference and use standard errors that are two-way clustered at both the origin and destination levels throughout.

Table 3 presents OLS estimates of equation (16). We begin in column (1) with a specification designed to estimate $\tilde{\beta}_{M}$ as accurately as possible. To do so we control for an origin-disease fixed-effect (rather than including the origin country's predicted disease burden). While the estimate of $\tilde{\beta}_{M}>0$ seen there should not be surprising-that a demand shifter in the destination country is positively correlated with greater purchases by that destination-this can be thought of as a check on the validity and power of demographic variation for predicting drug expenditure. Column (2) proceeds with an analogous specification designed to estimate $\tilde{\beta}_{X}$ alone, as accurately as possible, while controlling for a destination-disease fixed-effect. The estimated value of $\tilde{\beta}_{X}$ is clearly positive and statistically significant. This result provides a resounding rejection of the absence of a weak home-market effect (or equivalently, means that the probability that the weak home-market effect operates in this context is high).

Finally, column (3) estimates $\tilde{\beta}_{M}$ and $\tilde{\beta}_{X}$ simultaneously in the true spirit of equation (7). This is our preferred specification. We first note that the estimates of $\tilde{\beta}_{M}$ and $\tilde{\beta}_{X}$ in column (3) are very similar to those in columns (1) and (2), so evidence for the weak home-

\footnotetext{
${ }^{17}$ There are two reasons why the previous assumption may be violated. First, government funding of medical research may reflect, at least in part, the needs of the local population; see Lichtenberg (2001). Second, clinical trials may be cheaper to conduct in countries with a large pool of potential subjects. If so, one would expect the supply shifter $\eta_{i}^{n}$, and hence the residual, $\tilde{\varepsilon}_{i j}^{n}$, to be an increasing function of $\ln (P D B)_{i}^{n}$,

$$
\tilde{\varepsilon}_{i j}^{n}=\beta \ln (P D B)_{i}^{n}+v_{i j}^{n}
$$

with $\beta>0$ and $v_{i j}^{n}$ uncorrelated with $\ln (P D B)_{i}^{n}$. In such cases, it is important to note that our empirical test of the home-market would remain valid in the sense that we could still estimate (16) using OLS to test whether an increase in domestic demand, as proxied by $\ln (P D B)_{i}^{n}$, tends to raise exports. The structural interpretation of the estimated elasticities, however, would change. For instance, in the case of a small open economy discussed in Section 3.2, the OLS estimate of the elasticity of $\ln x_{i j}^{n}$ with respect to $\ln (P D B)_{i}^{n}$ would now be equal to the sum of $\gamma \lambda\left(1-\epsilon^{x}\right) /\left(\epsilon^{\mathcal{s}}+\epsilon^{w}\right)$ and $\beta$.
} 
Table 3: Test of the Home-Market Effect (baseline)

\begin{tabular}{lccc}
\hline & \multicolumn{3}{c}{$\log$ (bilateral sales) } \\
\cline { 2 - 4 } & $(1)$ & $(2)$ & $(3)$ \\
\hline $\log (\mathrm{PDB}$, destination) & 0.526 & & 0.563 \\
& $(0.098)$ & & $(0.109)$ \\
$\log (\mathrm{PDB}$, origin) & & 0.932 & 0.918 \\
& & $(0.174)$ & $(0.122)$ \\
& & & \\
p-value for $H_{0}: \tilde{\beta}_{X} \leq 0$ & & $0.000^{* * *}$ & $0.000^{* * *}$ \\
p-value for $H_{0}: \tilde{\beta}_{X} \leq \tilde{\beta}_{M}$ & & & $0.027^{* *}$ \\
\hline Origin $\times$ disease FE & $\checkmark$ & & \\
Destination $\times$ disease FE & & & \\
Disease FE & & & $\checkmark$ \\
\hline Adjusted $R^{2}$ & 0.629 & 0.562 & 0.539 \\
Observations & 18,857 & 19,008 & 19,255 \\
\hline
\end{tabular}

Notes: OLS estimates of equation (16). Predicted disease burden $\left(P D B_{i}^{n}\right)$ is constructed from an interaction between the global (leaving out country $i$ ) disease burden by demographic group in disease $n$, and the size of each demographic group in country $i$. All regressions omit the bilateral sales observation for home sales (i.e. where $i=j$ ) and control for origin-times-destination fixed-effects. The number of observations differs across columns due to omission of observations that are completely accounted for by the included fixed-effects. Standard errors in parentheses are two-way clustered at origin and destination country levels. $\mathrm{p}$-values are based on F-test of the stated $H_{0}{ }^{* * *} \mathrm{p}<0.01,{ }^{* *} \mathrm{p}<0.05$.

market effect remains firm. And the p-value on the F-test for $\tilde{\beta}_{X} \leq \tilde{\beta}_{M}$ is 0.027 , implying that the absence of a strong home-market effect can be rejected at the five percent level. That is, the balance of probability speaks in favor of the strong home-market effect taking place in the pharmaceutical sector.

\subsection{Sensitivity Analysis}

Having established these simple facts about the weak and strong home-market effects in the global pharmaceutical sector, we now seek, in the remainder of this section, to explore the robustness of these estimates to various changes in the empirical specification. Throughout, we focus on estimates of equation (16), and hence on tests for both the weak and the strong home-market effect.

We begin in Table 4 by repeating in column (1), for the sake of comparison, our baseline estimate from Table 3. This baseline specification uses all bilateral sales observations $x_{i j}^{n}$ that are positive and for which $i \neq j$. Column (2) then assesses the extent to which 
Table 4: Test of the Home-Market Effect (sensitivity analysis I)

\begin{tabular}{lccccc}
\hline & \multicolumn{5}{c}{$\log ($ bilateral sales $)$} \\
\cline { 2 - 6 } & $(1)$ & $(2)$ & $(3)$ & $(4)$ & $(5)$ \\
\hline $\log$ (PDB, destination) & 0.563 & 0.530 & 0.648 & 0.540 & 0.417 \\
& $(0.109)$ & $(0.104)$ & $(0.114)$ & $(0.105)$ & $(0.101)$ \\
$\log$ (PDB, origin) & 0.918 & 0.828 & 0.894 & 0.727 & 0.833 \\
& $(0.122)$ & $(0.099)$ & $(0.112)$ & $(0.172)$ & $(0.115)$ \\
& & & & & \\
p-value for $H_{0}: \tilde{\beta}_{X} \leq 0$ & $0.000^{* * *}$ & $0.000^{* * *}$ & $0.000^{* * *}$ & $0.000^{* * *}$ & $0.000^{* * *}$ \\
p-value for $H_{0}: \tilde{\beta}_{X} \leq \tilde{\beta}_{M}$ & $0.027^{* *}$ & $0.038^{* *}$ & $0.081^{*}$ & 0.152 & $0.008^{* * *}$ \\
\hline Home sales $\left(X_{i i}^{n}\right.$ obs. incl. & & $\checkmark$ & & & \\
All origins included & & & & & \\
Disease FE $\times$ origin p.c. GDP & & & & $\checkmark$ & \\
Disease FE $\times$ dest. p.c. GDP & & & & & $\checkmark$ \\
Origin FE $\times$ disease decile & & & & & $\checkmark .535$ \\
Dest. FE $\times$ disease decile & & & & & \\
\hline Adjusted $R^{2}$ & 0.539 & 0.562 & 0.539 & 0.560 \\
Observations & 19,255 & 21,382 & 21,914 & 19,255 & 19,206 \\
\hline
\end{tabular}

Notes: OLS estimates of equation (16). All specifications control for origin-destination fixed-effects and disease fixed-effects. "Disease decile" in column (5) represents the decile, of the worldwide distribution based on total disease burden, in which a given disease falls. See Table 3 for details on construction of variables, sample restrictions, and calculation of standard errors (reported in parentheses) and $\mathrm{p}$-values. ${ }^{* * *} \mathrm{p}<0.01,{ }^{* *} \mathrm{p}<0.05,{ }^{*} \mathrm{p}<0.1$.

including home sales observations (those for which $i=j$ ) affects our estimates of the home-market effect-evidently, this specification decision has little bearing on our estimates. Column (3) confirms that the same is true about our decision to use in our baseline analysis the sample in which origin countries are only included if they can also appear as destinations; including all possible origin countries has relatively little impact on our estimates.

Column (4) of Table 4 tests for the two home-market effects in a demanding specification that also simultaneously controls for interactions between the origin country's per-capita GDP and disease fixed-effects, as well as for the analogous variable on the destination country side. In this specification, the standard errors rise, as expected given the number of regressors that are now being estimated. In turn, while the null of no weak home-market effect can still be rejected at standard confidence levels, this is no longer true for the null of strong home-market effect. Reassuringly, the point estimates of $\tilde{\beta}_{M}$ and $\tilde{\beta}_{X}$ 
have not changed much in comparison with the estimates in column (1). This suggests that although there may be some systematic tendency for poor countries to produce certain drugs-in line, for instance, with Vernon's (1966) product cycle hypothesis-these drugs do not happen to treat the diseases associated with poor country demographics.

Finally, in column (5) we report a specification that controls for interactions between country (origin and destination) fixed-effects and a measure of disease intensity (the decile in which a disease falls in the worldwide distribution, based on its disease burden). Again, the stability of the key coefficients, $\tilde{\beta}_{M}$ and $\tilde{\beta}_{X}$ implies that they are being identified from the intended demographic-related component of disease burden, rather than some other pattern related to disease burden more generally.

In Tables 5, 6, and 7, we continue to explore the robustness of our results. Starting with Table 5, column (1) again repeats our baseline estimate for the purpose of comparison. Column (2) demonstrates that our estimates are not being driven by the largest global drug-selling countries: dropping the five largest such countries does not much change the estimated coefficients. Column (3) asks whether the results of Table 3 are being driven by poor origin or destination countries and the answer appears to be resoundingly in the negative: our coefficient estimates are remarkably stable to changing the countries in the sample on the basis of their GDP per capita levels. ${ }^{18}$ Admittedly, that this is true should not come as much of a surprise given the results in column (4) of Table 4, documenting insensitivity to a rich set of interactions between the income level of the origin and destination countries. Like in Table 4, we can always reject the null of no weak home-market effect, whereas whether we can reject the null of no strong home-market effect varies across specifications.

The final column of Table 5 estimates interactions between PDB in the origin country and the share of that country in global sales (across all diseases), and analogously for the destination country. The home-market effect is clearly stronger for countries with a larger global market share, as would be expected, ceteris paribus, to the extent that larger countries have a stronger capacity to affect world prices.

Provided that our first-order approximation around a symmetric equilibrium is valid, our test of the market-effect does not require any restriction on the spatial correlation of demand shocks across countries, as mentioned in Section 3.2. Away from this symmetric benchmark, however, demand shocks in third countries may not be absorbed by our disease fixed-effect. Table 6 explores the potential importance of such considerations. Again,

\footnotetext{
${ }^{18}$ In a specification dropping only the poorest third of origin countries we estimate $\tilde{\beta}_{X}=0.980(0.229)$ and $\tilde{\beta}_{M}=0.542(0.103)$; similarly, when dropping only the poorest third of destination countries we estimate $\tilde{\beta}_{X}=0.918(0.162)$ and $\tilde{\beta}_{M}=0.680(0.112)$.
} 
Table 5: Test of the Home-Market Effect (sensitivity analysis II)

\begin{tabular}{|c|c|c|c|c|}
\hline & & $\log$ (bilat & 1 sales) & \\
\hline & (1) & (2) & (3) & (4) \\
\hline $\log (\mathrm{PDB}$, destination) & $\begin{array}{c}0.563 \\
(0.109)\end{array}$ & $\begin{array}{c}0.696 \\
(0.196)\end{array}$ & $\begin{array}{c}0.661 \\
(0.112)\end{array}$ & $\begin{array}{c}0.536 \\
(0.103)\end{array}$ \\
\hline $\log (\mathrm{PDB}$, origin $)$ & $\begin{array}{c}0.918 \\
(0.122)\end{array}$ & $\begin{array}{c}0.674 \\
(0.159)\end{array}$ & $\begin{array}{c}0.844 \\
(0.297)\end{array}$ & $\begin{array}{c}0.828 \\
(0.142)\end{array}$ \\
\hline $\log (\mathrm{PDB}$, dest. $) \times($ dest. sales share $)$ & & & & $\begin{array}{c}0.280 \\
(0.132)\end{array}$ \\
\hline $\log (\mathrm{PDB}$, origin $) \times($ origin sales share $)$ & & & & $\begin{array}{c}0.687 \\
(0.093)\end{array}$ \\
\hline $\begin{array}{l}\text { p-value for } H_{0}: \tilde{\beta}_{X} \leq 0 \\
\text { p-value for } H_{0}: \tilde{\beta}_{X} \leq \tilde{\beta}_{M}\end{array}$ & $\begin{array}{l}0.000^{* * *} \\
0.027^{* *}\end{array}$ & $\begin{array}{c}0.000^{* * *} \\
0.533\end{array}$ & $\begin{array}{c}0.004^{* * *} \\
0.264\end{array}$ & $\begin{array}{c}0.000^{* * *} \\
0.059^{*}\end{array}$ \\
\hline $\begin{array}{l}\text { Drop largest } 5 \text { origins } \\
\text { Drop poorest } 1 / 3 \text { origins } \\
\text { Drop poorest } 1 / 3 \text { dest. }\end{array}$ & & $\checkmark$ & $\begin{array}{l}\checkmark \\
\checkmark\end{array}$ & \\
\hline $\begin{array}{l}\text { Adjusted } R^{2} \\
\text { Observations }\end{array}$ & $\begin{array}{c}0.539 \\
19,255\end{array}$ & $\begin{array}{l}0.461 \\
9,242\end{array}$ & $\begin{array}{c}0.541 \\
11,253\end{array}$ & $\begin{array}{c}0.541 \\
19,255\end{array}$ \\
\hline
\end{tabular}

Notes: OLS estimates of equation (16). All specifications control for origin-destination fixed-effects and disease fixed-effects. "Destination sales share" is the share of global sales (across all diseases) made by firms based in the destination country; "origin sales share" is analogous. p-values in column (4) relate to tests of coefficients on $\log (\mathrm{PDB}$, destination) and $\log (\mathrm{PDB}$, origin). See Table 3 for details on construction of variables, sample restrictions, and calculation of standard errors (reported in parentheses) and p-values. *** $\mathrm{p}<0.01,{ }^{* *} \mathrm{p}<0.05,{ }^{*} \mathrm{p}<0.1$

column (1) repeats our baseline estimate for the purpose of comparison. Columns (2) and (3) show that restricting sales to a "donut" of destination countries, either located at more than $1,000 \mathrm{~km}$ or $2,000 \mathrm{~km}$ from the home market, has little effect on our estimates. ${ }^{19}$ The same is true in column (4) when we control for the average disease burdens in all other countries, weighted by their distance to the origin and destination country; formally, we estimate a version of equation (16) that also includes the regressors $\sum_{k \neq i} \ln P D B_{k}^{n} \cdot d_{i s t}^{-1}$ and $\sum_{k \neq j} \ln P D B_{k}^{n} \cdot d i s t_{k j}^{-1}$. Put together, these results imply that multilateral considerations do not appear to be first-order in our setting.

Table 7 presents results designed to assess three final potential concerns. First, it is possible that our baseline results are biased downwards due to the fact that a country's

\footnotetext{
${ }^{19}$ Data on bilateral country pair distance are from the CEPII Gravity dataset; see Head and Mayer (2010).
} 
Table 6: Test of the Home-Market Effect (sensitivity analysis III)

\begin{tabular}{lcccc}
\hline & \multicolumn{4}{c}{$\log ($ bilateral sales $)$} \\
\cline { 2 - 5 } & $(1)$ & $(2)$ & $(3)$ & $(4)$ \\
\hline $\log$ (PDB, destination) & 0.563 & 0.567 & 0.623 & 0.559 \\
& $(0.109)$ & $(0.114)$ & $(0.089)$ & $(0.108)$ \\
$\log$ (PDB, origin) & 0.918 & 0.933 & 0.820 & 0.917 \\
& $(0.122)$ & $(0.145)$ & $(0.167)$ & $(0.126)$ \\
& & & & \\
p-value for $H_{0}: \tilde{\beta}_{X} \leq 0$ & $0.000^{* * *}$ & $0.000^{* * *}$ & $0.000^{* * *}$ & $0.000^{* * *}$ \\
p-value for $H_{0}: \tilde{\beta}_{X} \leq \tilde{\beta}_{M}$ & $0.027^{* *}$ & $0.046^{* *}$ & 0.172 & $0.027^{* *}$ \\
\hline Sample of only $i j$ obs. with dist $t_{i j} \geq$ & - & $1,000 \mathrm{~km}$ & $2,000 \mathrm{~km}$ & - \\
Control for $\sum_{k \neq i} \ln P D B_{k}^{n} \cdot$ dist $_{i k}^{-1}$ & & & & $\checkmark$ \\
Control for $\sum_{k \neq j} \ln P D B_{k}^{n} \cdot$ dist $_{k j}^{-1}$ & & & & $\checkmark$ \\
\hline Adjusted $R^{2}$ & 0.539 & 0.538 & 0.549 & 0.539 \\
Observations & 19,255 & 16,676 & 13,459 & 19,255 \\
\hline
\end{tabular}

Notes: OLS estimates of equation (16). All specifications control for origin-destination fixed-effects and disease fixed-effects. See Table 3 for details on construction of variables, sample restrictions, and calculation of standard errors (reported in parentheses) and p-values. ${ }^{* * *} \mathrm{p}<0.01,{ }^{* *} \mathrm{p}<0.05$.

demographic composition could itself be shaped by its disease environment-in the extreme, if a disease were to completely eradicate a demographic group in a country then there would no longer be any demand there for drugs to treat that disease. We therefore compare the effect of constructing our predicted disease burden (PDB) regressors from countries' lagged demographic composition (in column 2, 1996 demographics) relative to our baseline estimate (column 1, based on 2012 demographics). ${ }^{20}$ That the estimates of $\tilde{\beta}_{M}$ and $\tilde{\beta}_{X}$ are similar suggests that this extreme form of reverse causation is not quantitatively plausible in our setting. Second, we disaggregate our analysis into two different types of drugs: generics (where the original molecule is no longer subject to intellectual property protection and hence is free to be produced by any firm) and branded drugs (on which intellectual property rights still apply). Column (3) illustrates how the weak homemarket effect remains an important feature of the data, even purely among generic drug sales. Perhaps as expected, the coefficient in column (3) is smaller than that in column (1), suggesting that sector-level economies of scale may be less important for generic drugs than for branded drugs; indeed, within this generics sub-sector of the pharmaceutical in-

\footnotetext{
${ }^{20}$ This specification draws on demographic data (in the PDB variable) from 1996, the earliest year for which data are available on the demographic composition spanning a wide set of countries.
} 
Table 7: Test of the Home-Market Effect (sensitivity analysis IV)

\begin{tabular}{lcccc}
\hline & \multicolumn{4}{c}{$\log ($ bilateral sales $)$} \\
\cline { 2 - 5 } & $(1)$ & $(2)$ & $(3)$ & $(4)$ \\
\hline $\log$ (PDB, destination) & 0.563 & 0.559 & 0.544 & 0.076 \\
& $(0.109)$ & $(0.103)$ & $(0.211)$ & $(0.476)$ \\
$\log$ (PDB, origin) & 0.918 & 0.779 & 0.395 & 0.695 \\
& $(0.122)$ & $(0.101)$ & $(0.126)$ & $(0.295)$ \\
& & & & \\
p-value for $H_{0}: \tilde{\beta}_{X} \leq 0$ & $0.000^{* * *}$ & $0.000^{* * *}$ & $0.001^{* * *}$ & $0.014^{* *}$ \\
p-value for $H_{0}: \tilde{\beta}_{X} \leq \tilde{\beta}_{M}$ & $0.027^{* *}$ & $0.077^{*}$ & 0.717 & 0.137 \\
\hline$P D B_{i}^{n}, P D B_{j}^{n}$ using 1996 demographics & & $\checkmark$ & & \\
Generic drugs only & & & & $\checkmark$ \\
EU destinations only & & & & $\checkmark$ \\
\hline Adjusted $R^{2}$ & 0.539 & 0.539 & 0.474 & 0.535 \\
Observations & 19,255 & 19,255 & 8,791 & 7,282 \\
\hline
\end{tabular}

Notes: OLS estimates of equation (16). All specifications control for origin-destination fixed-effects and disease fixed-effcts. See Table 3 for details on construction of variables, sample restrictions, and calculations of standard errors (reported in parentheses) and p-values. ${ }^{* * *} \mathrm{p}<0.01,{ }^{* *} \mathrm{p}<0.05,{ }^{*} \mathrm{p}<0.1$.

dustry, it appears that economies of scale are not strong enough to generate the strong home-market effect. A final potential concern is that firms in our setting can engage in substantial pricing-to-market, due to prohibitions on international resale, and hence that the non-arbitrage equation (5) may not apply. One way of assessing this is to limit the sample of destination markets to those within the EU, a free trade area within which pharmaceutical firms cannot prevent international resale. As can be seen in column (4), our estimates are quite similar in the EU sample, suggesting that potential violations of equation (5), and ensuing implications for for our test of the home-market effect, are not a major concern.

In Table 8 we conclude with estimates of the home-market effect along the extensive margin - that is, whether a foreign market is penetrated at all. Given that our previous results (in Tables 3-7 above) used the log of bilateral sales $\left(x_{i j}^{n}\right)$ as the dependent variable, any country pair-disease observations with zero bilateral sales were omitted from the estimation sample. Therefore, for completeness, we present in column (2) results from Poisson Pseudo-Maximum Likelihood (PPML) estimation, a standard alternative estimation approach to gravity-like estimation in the presence of zeroes in the dependent variable (see, for example, Head and Mayer, 2013). While the (two-way clustered) standard errors 
Table 8: Test of the Home-Market Effect (extensive margin)

\begin{tabular}{|c|c|c|c|c|}
\hline & \multicolumn{2}{|c|}{$\log$ (bilateral sales) } & \multicolumn{2}{|c|}{$\mathbb{1}$ (bilateral sales $>0$ ) } \\
\hline & (1) & (2) & (3) & (4) \\
\hline $\log$ (PDB, destination) & $\begin{array}{c}0.563 \\
(0.109)\end{array}$ & $\begin{array}{c}0.383 \\
(0.149)\end{array}$ & $\begin{array}{c}0.008 \\
(0.004)\end{array}$ & $\begin{array}{c}0.009 \\
(0.004)\end{array}$ \\
\hline $\log (\mathrm{PDB}$, origin $)$ & $\begin{array}{c}0.918 \\
(0.122)\end{array}$ & $\begin{array}{c}1.272 \\
(0.515)\end{array}$ & $\begin{array}{c}0.055 \\
(0.013)\end{array}$ & $\begin{array}{c}0.063 \\
(0.013)\end{array}$ \\
\hline $\begin{array}{l}\text { p-value for } H_{0}: \tilde{\beta}_{X} \leq 0 \\
\text { p-value for } H_{0}: \tilde{\beta}_{X} \leq \tilde{\beta}_{M}\end{array}$ & $\begin{array}{l}0.000^{* * *} \\
0.027^{* *}\end{array}$ & $\begin{array}{c}0.007^{* * *} \\
0.065^{*}\end{array}$ & $\begin{array}{l}0.000^{* * *} \\
0.000^{* * *}\end{array}$ & $\begin{array}{l}0.000^{* * *} \\
0.000^{* * *}\end{array}$ \\
\hline $\begin{array}{l}\text { PPML estimator } \\
\text { Disease FE } \times \text { origin GDP } / \text { capita } \\
\text { Disease FE } \times \text { destination GDP } / \text { capita }\end{array}$ & & $\checkmark$ & & $\begin{array}{l}\checkmark \\
\checkmark\end{array}$ \\
\hline $\begin{array}{l}\text { Adjusted } R^{2} \\
\text { Observations }\end{array}$ & $\begin{array}{c}0.539 \\
19,255\end{array}$ & $\begin{array}{c}0.407 \\
178,640\end{array}$ & $\begin{array}{c}0.487 \\
178,640\end{array}$ & $\begin{array}{c}0.500 \\
178,640\end{array}$ \\
\hline
\end{tabular}

Notes: Column (1) reports OLS estimates, column (2) Poisson Psuedo-Maximum Likelihood (PPML) estimates, and columns (3) and (4) linear probability model estimates, based on equation (16). Pseudo- $R^{2}$ reported in column (2). All specifications control for origin-destination fixed-effects and disease fixed-effects. See Table 3 for details on construction of variables, sample restrictions, and calculations of standard errors (reported in parentheses) and p-values. ${ }^{* * *} \mathrm{p}<0.01,{ }^{* *} \mathrm{p}<0.05$.

on this estimate are larger than their OLS analogs (in column 1), we still reject the lack of a weak and a strong home-market effect (at the 1 and 10 percent levels, respectively). Columns (3) and (4) go on to estimate a specification in which the dependent variable is no longer the $(\log )$ level of $x_{i j}^{n}$ but a dummy variable for whether bilateral sales take place (i.e. $x_{i j}^{n}>0$ ) or not. For simplicity, we estimate this as a linear probability model. There is strong support in these two columns-whether a full set of disease fixed-effect interactions with country living standards is included or not-for the idea that home demand shocks also lead to more exports abroad along the extensive margin.

\section{Disentangling Demand and Supply Elasticities}

The results of Section 5 provide indelible support for the notion of a home-market effect in the global pharmaceutical sector. But, as discussed in Section 3, weak and strong home-market effects depend both on demand and supply elasticities. Thus, the structural interpretation of the previous effect remains open. Does the home-market effect reflect the presence of economies of scale at the sector-level or merely a low elasticity of demand? 
And if it does indeed reflect economies of scale, how large are they? We now address these questions.

\subsection{Estimating the Elasticity of Demand}

Around a symmetric equilibrium, bilateral sales can be expressed, up to a first-order approximation, as

$$
\ln x_{i j}^{n}=\delta_{j}^{n}+\left(1-\epsilon^{x}\right) \ln p_{i}^{n}+\left(1-\epsilon^{x}\right) \ln \tau_{i j}^{n}
$$

where $\delta_{j}^{n}$ is a destination-disease fixed-effect. ${ }^{21}$ We aim here to estimate the price elasticity of exports, $\epsilon^{x}$. Our approach proceeds in two steps. First, we estimate the elasticity of trade costs with respect to distance. And second, we estimate the elasticity of exports with respect to distance. Then, by equation (17), $1-\epsilon^{x}$ is given by the ratio of the second elasticity over the first.

\section{Distance elasticity of trade costs}

Suppose that, up to a first-order approximation, trade $\operatorname{costs} \tau_{i j}^{n}$ can be expressed as

$$
\ln \tau_{i j}^{n}=\alpha \ln \operatorname{dist}_{i j}+v_{i j}^{n}
$$

where dist $_{i j}$ is the physical distance between country $i$ and country $j$ and $v_{i j}^{n}$ is the component of trade costs not explained by distance. We use micro-data on prices of individual drugs in order to identify $\alpha$. For any individual variety of a drug $\omega$ within the class of drugs that treat disease $n$, suppose that prices satisfy

$$
p_{i j}^{n}(\omega)=\tau_{i j}^{n} p_{i}^{n}(\omega) .
$$

This condition mandates that the price at which the same variety $\omega$ sells, after adjusting for trade costs, is the same across destination markets. Substituting (18) into (19), we have

$$
\ln p_{i j}^{n}(\omega)=\alpha \ln d i s t_{i j}+\ln p_{i}^{n}(\omega)+v_{i j}^{n}
$$

Thus we can obtain an unbiased estimate of $\alpha$ using OLS to estimate the following specification

$$
\ln p_{i j}^{n}(\omega)=\alpha \ln \operatorname{dist}_{i j}+\delta_{i}^{n}(\omega)+\delta_{i j}^{n}(\omega),
$$

\footnotetext{
${ }^{21}$ Details can be found in Appendix D. The expression in equation (17) is valid, up to a first-order approximation, for any demand system that can be written in the form of equations (1)-(3). But this expression becomes valid (globally and without approximation) in the commonly applied case where the function $d(\cdot)$ in equation(2) is CES.
} 
Table 9: Demand elasticity estimates

\begin{tabular}{|c|c|c|}
\hline & $\log$ (price) & $\log ($ bilateral sales $)$ \\
\hline & (1) & (2) \\
\hline $\log$ (bilateral distance) & $\begin{array}{c}0.064 \\
(0.031)\end{array}$ & $\begin{array}{c}-0.302 \\
(0.073)\end{array}$ \\
\hline $\begin{array}{l}\text { Variety FE } \\
\text { Origin } \times \text { disease FE } \\
\text { Destination } \times \text { disease FE }\end{array}$ & $\checkmark$ & $\begin{array}{l}\checkmark \\
\checkmark\end{array}$ \\
\hline $\begin{array}{l}\text { Adjusted } R^{2} \\
\text { Observations }\end{array}$ & $\begin{array}{c}0.881 \\
64,642\end{array}$ & $\begin{array}{c}0.573 \\
18,740\end{array}$ \\
\hline
\end{tabular}

Notes: Column (1) reports OLS estimates of equation (20); variety fixed-effects control for interactions between all combinations of active molecules, corporations, and disease classes; standard errors (in parentheses) clustered by destination country. Column (2) reports OLS estimates of equation (21). Standard errors in parentheses are two-way clustered at origin and destination country levels. All regressions omit the bilateral sales observation for home sales (i.e where $i=j$ ).

where $\delta_{i}^{n}(\omega)$ is a variety fixed-effect and $\delta_{i j}^{n}(\omega)$ is an error term. ${ }^{22}$ The basic idea here is that if a given variety sells in many destination countries, then the extent to which the prices of that disease vary across destinations $j$ that are different distances $d_{i s} t_{i j}$ from the producer's origin country $i$ identifies $\alpha$.

The results from estimating equation (20) are reported in Table 9 (column 1). Distance is evidently a statistically significant shifter of costs at distant destination locations and is positively correlated with the retail price (for the same variety, sold from the same origin), despite the manifold reasons for retail prices to vary across consumer markets in the pharmaceutical sector. As might be expected, given the relatively high weight-tovalue of pharmaceutical products, and given that our data track total foreign sales (not just exports), the effect of distance on prices (captured by the parameter $\alpha$ ) is low relative to analogous estimates (for all traded merchandise sectors) in the literature. For example, Head and Mayer (2013) report a preferred distance elasticity of -0.89 and a preferred trade elasticity of -5.03 . Together, these estimates imply $\alpha=0.18$, which is nearly three times larger than our estimate of $\alpha=0.064$.

\footnotetext{
${ }^{22}$ By "variety" we refer, in practice, to the permutation of physiologically active molecules (since some drugs contain more than one active molecule), interacted with the disease for which the drug is intended to treat (since, in rare cases, the same molecule can be marketed in separate therapeutical classes), and interacted with the firm selling the drug.
} 


\section{Distance elasticity of sales}

Substituting for trade costs in (17) using (18), we obtain

$$
\ln x_{i j}^{n}=\delta_{j}^{n}+\delta_{i}^{n}+\rho \ln d i s t_{i j}+\chi_{i j}^{n}
$$

with $\rho \equiv\left(1-\epsilon^{x}\right) \alpha, \chi_{i j}^{n} \equiv\left(1-\epsilon^{x}\right) v_{i j}^{n}$, and $\delta_{i}^{n}$ representing an origin-drug fixed-effect. As before, we estimate this equation with OLS. Our estimate of $\rho$ is reported in Table 9, column (2). As is commonly found in estimates of the gravity equation (21), bilateral distance has a negative and statistically significant impact on impeding bilateral drug sales in this setting. But again, as with our discussion of $\alpha$ above, the estimated effect of distance on trade is about three times lower than typical estimates from trade data in other sectors.

\section{Elasticity of demand}

The identity $\rho \equiv\left(1-\epsilon^{x}\right) \alpha$ implies that $\epsilon^{x}=1-\rho / \alpha$. Given the estimates in Table 9, this implies that $\epsilon^{x}=5.72$, with a destination country block-bootstrapped $95 \%$ confidence interval of $[3.04,32.61]{ }^{23}$ This implies that cross-disease demand is elastic in the present setting. As per the discussion in Section 3.2, this then implies that, at least for a small open economy, the tests for the weak and strong home-market effects reported in Section 5.1 provide bounds on economies of scale. For example: we know that the evidence for the weak home-market effect reported in Table 1 implies that industry-level (positive) economies of scale are at work in this setting. Naturally, such a bound is of only limited use for quantitative policy questions so we turn now to a method that uses the demand elasticity estimate here in order to obtain a point estimate of the elasticity of supply.

\subsection{Estimating the Elasticity of Supply}

Let $r_{i}^{n} \equiv p_{i}^{n} s_{i}^{n}$ denote the total sales of drugs targeting disease $n$ by firms from country $i$. Around a symmetric equilibrium, up to a first-order approximation, the supply relation in equation (5) can be written as

$$
\ln r_{i}^{n}=\left(1+\epsilon^{\mathcal{S}}\right) \ln p_{i}^{n}+\ln \eta_{i}^{n}
$$

\footnotetext{
${ }^{23}$ We are unaware of a block-bootstrap procedure that is analogous to two-way clustering. But this does not appear to be a setting where the difference between two-way clustering (on origin and destination) is substantially different from simply clustering on either origin or destination-for example, the standard error in column (2) of Table 9 is 0.056 when clustering on destination country.
} 
Using the previous expression to substitute for $p_{i}^{n}$ in equation (17), we obtain

$$
\ln x_{i j}^{n}=\delta_{j}^{n}+\delta_{i j}+\left(\frac{1-\epsilon^{x}}{1+\epsilon^{s}}\right) \ln r_{i}^{n}+\phi_{i j}^{n}
$$

with $\delta_{i j}$ representing an origin-destination fixed-effect and $\phi_{i j}^{n} \equiv \chi_{i j}^{n}-\bar{\chi}_{i j}^{n}-\left(\frac{1-\epsilon^{x}}{1+\epsilon^{s}}\right) \ln \eta_{i}^{n}$. OLS estimates of equation (22) would be biased because both the supply shock $\eta_{i}^{n}$ and unobserved trade costs $\chi_{i j}^{n}$ in the error term $\phi_{i j}^{n}$ contributes to total sales $r_{i}^{n}$. But for all destination observations $j \neq i$, an exogenous shifter of demand at the origin country $i$ (such as the predicted disease burden variable $P D B_{i}^{n}$ introduced in equation 14) can be used as a valid instrumental variable for $r_{i}^{n} .{ }^{24}$ Such an IV estimation procedure identifies $\left(\frac{1-\epsilon^{x}}{1+\epsilon^{s}}\right)$, which, combined with the estimate of $\epsilon^{x}$ from above, identifies the slope of the supply curve given by $\epsilon^{s}$.

Table 10 reports estimates from specification (22). We begin in column (1) by reporting the first-stage regression of $\ln r_{i}^{n}$ on $\ln P D B_{i}^{n}$, conditional on origin-destination and destination-disease fixed-effects. That predicted disease burden is strongly correlated with total sales (the F-statistic on this excluded instrument is equal to 123.05, the square of the $t$-statistic from column 1) should come as no surprise given the results in Table 3. Column (2) then reports the OLS estimate of equation (22) and column (3) the corresponding IV estimate. ${ }^{25}$ This (statistically significant) IV estimate implies that $\left(\frac{1-\epsilon^{x}}{1+\epsilon^{s}}\right)=0.779$. Given our estimate of $\epsilon^{x}=5.72$ from above, this implies that $\epsilon^{\mathcal{S}}=-7.06$ (with destination country block-bootstrapped $95 \%$ confidence interval of $[-41.95,-3.89])$. As expected, given the bounds implied by the weak home-market effect discussed above, the estimated industry-level supply curve in this setting is downward-sloping, indicating returns to scale.

How does this estimate of $\epsilon^{\mathcal{S}}$ compare to those in prior work? Both empirical and theoretical findings offer points of reference. From the empirical literature, one strand aims to estimate industry-level economies of scale directly, via industry-level production functions. A prominent estimate (pooled among all U.S. manufacturing sectors, so unfortunately not available for the pharmaceutical sector alone) from Basu and Fernald (1997)

\footnotetext{
${ }^{24}$ Because $r_{i}^{n} \equiv \sum_{j} x_{i j}^{n}$, equation (22) is a log-linear analog of the canonical peer effects regression discussed in, for example, Manski (1993) — where the regressor of interest is the sum (or mean) of the dependent variable within some peer group. As is well known, identification of such peer effects is impossible without instruments that shift the actions of an agent's peers (and hence also the sum of all peers' actions) but do not affect the agent's own payoff function directly. Our instrument, $P D B_{i}^{n}$, plays an analogous role here (given our focus on observations for which $j \neq i$ ).

${ }^{25}$ The fact that the OLS estimate in column (2) is smaller than the IV estimate in column (3) is consistent with downward-sloping supply curves since when $\epsilon^{\mathcal{S}}<-1$ (and given elastic demand, $\epsilon^{x}>1$ ) the error term $\phi_{i j}^{n}$ in equation (22) depends negatively on the supply shock $\eta_{i}^{n}$.
} 
Table 10: Supply elasticity estimates

$\frac{\log (\text { total sales })}{\text { OLS }} \frac{\log (\text { bilateral sales })}{\text { OLS IV }}$

(1)

(2)

$\log (\mathrm{PDB})$

1.197

(0.108)

$\log$ (total sales)

0.666

0.779

$(0.053)$

$(0.122)$

p-value for $H_{0}:\left(\frac{1-\epsilon^{x}}{1+\epsilon^{s}}\right)=1$

$0.075^{*}$

Adjusted $R^{2}$

0.788

0.627

0.625

Observations

19,008

19,008

19,008

Notes: Column (2) reports the OLS estimate, and column (3) the IV estimate, of equation (22). Column (1) reports the corresponding first-stage specification. The instrumental variable is $\log (\mathrm{PDB})$ in the origin country. All regressions omit the bilateral sales observation for home sales (i.e where $i=j$ ) and control for orign-destination and destination-disease fixed-effects. Standard errors in parentheses are two-way clustered at origin and destination country levels. $p$-value is based on F-test of $H_{0}{ }^{*} \mathrm{p}<0.1$.

estimates industry-level economies of scale that generate an industry-level supply curve with $\epsilon^{\mathcal{S}}=-4.45$. A second strand, initiated by Antweiler and Trefler, 2002, uses patterns of comparative advantage revealed in international trade data to infer relative costs for each country-industry, and then estimates the extent to which those inferred costs depend on scale. For the pharmaceutical industry Antweiler and Trefler's (2002) estimates imply $\epsilon^{\mathcal{S}}=-4.27$. Since lower supply elasticities in absolute value imply larger effects of quantity on producer prices, both of these estimates imply somewhat stronger economies of scale than found in our estimate of $\epsilon^{\mathcal{S}}=-7.06 .^{26}$ That said, neither of these estimates is based on an empirical strategy that isolates demand-side variation and is powerful enough to circumvent weak instrument concerns. ${ }^{27}$

\footnotetext{
${ }^{26}$ One possible reason for the stronger industry-level economies of scale found in these earlier studies, relative to ours, is that they are obtained from settings with more aggregate notions of an industry (a representative manufacturing sector in Basu and Fernald (1997) or the entire pharmaceutical sector in Antweiler and Trefler, 2002) than that used here (a representative disease class within the pharmaceutical sector).

${ }^{27} \mathrm{~A}$ third example of work that attempts to estimate industry-level economies of scale is due to Shea (1993), who finds that the industry-level supply curve slopes upwards in the pharmaceutical industry. This approach (when applied, for example, to the pharmaceutical sector) uses input-output table information to find a downstream sector that buys a substantial share of its inputs from the pharmaceutical sector, but which sources only a small share of its other inputs from sectors that themselves are not used substantially as inputs in the pharmaceutical sector. Output in such a sector can then be employed as a demand-side instrumental variable for output in the pharmaceutical sector (when estimating an inverse supply curve)
} 
The influential model of Krugman (1980) also provides a clear benchmark. As discussed in Section 3.3, this model is a special case in which there is a particularly stark connection between industry-level supply and demand elasticities: $\epsilon^{\mathcal{S}}=-\epsilon^{x}$. This implies that $\left(\frac{1-\epsilon^{x}}{1+\epsilon^{s}}\right)$, the coefficient reported in column (3) of Table 8, should be equal to one. Instead our IV estimate is equal to 0.779 , about $25 \%$ smaller. While the reported p-value demonstrates that the particular parameter value assumed in Krugman (1980) is rejected at the ten percent level, our estimate is certainly closer to this benchmark value than to the constant-returns extreme in which $\epsilon^{s}=\infty$ (and hence the coefficient in column 3 would be equal to zero).

\section{Concluding Remarks}

Since the home-market effect hypothesized by Linder (1961) and formalized by Krugman (1980) is about the causal effect of cross-country differences in demand on the pattern of international specialization, any empirical test of this phenomenon requires exogenous demand variation. In this paper, we have focused on the global pharmaceutical industry as a way to obtain such variation. Our empirical strategy builds on the basic observation that countries whose populations, because of exogenous demographic characteristics, are more likely to suffer from particular diseases are also more likely to have high demand for drugs targeting those diseases.

We have conducted tests of two different notions of the home-market effect. The first test, which is based on what we have referred to as the weak home-market effect, investigates whether countries tend to sell more abroad in sectors for which they have larger domestic markets. In the present context, this boils down to estimating whether the elasticity of a country's foreign sales with respect to its demographically predicted disease burden is positive. In line with the work of Linder (1961), the answer is a resounding yes. In short, the more we die (at home), the more we sell (abroad).

Our second test, defined by what we have referred to as the strong home-market effect, explores whether the previous effect can be important enough to turn countries with larger demand for some products into net sellers of those products, a stronger implication of Krugman's (1980) monopolistically competitive model. Our baseline results speak in favor of the strong home-market effect taking place in the pharmaceutical sector, though, in comparison with the weak home-market effect, we are not able to reject the null of no strong home-market effect in some of our specifications.

under the assumption that the two sectors do not face correlated demand shocks. 
To delve further into the economic determinants of the home-market effect, we have concluded our analysis by estimating demand and supply elasticities in the pharmaceutical industry. Our estimates point towards the home-market effect being driven by substantial economies of scale at the sector-level rather than a low elasticity of demand. Quantitatively, we have estimated a supply elasticity that is about three-quarters the size of what a monopolistically competitive model, like Krugman (1980), would predict. Recent quantitative work on international trade and economic geography has typically assumed, without attempting to estimate, economies of scale that are either zero, as in Eaton and Kortum (2002), or of Krugman's (1980) magnitude. In our context, both extremes are rejected by the data. Our analysis, however, demonstrates how a single supply-side parameter can nest these two cases, and how a plausibly exogenous demand shifter can let the data speak freely to this parameter's value.

Finally, we note that although our paper contains no welfare analysis, our results provide empirical support to the heterodox view that import protection may lead to export promotion, at least within the context of a specific, but important industry. 


\section{References}

Acemoglu, Daron and Joshua Linn, "Market size in innovation: Theory and evidence from the pharmaceutical industry," Quarterly Journal of Economics, 2004, 119 (3), 1049-1090.

Amiti, Mary, "Inter-industry trade in manufactures: does country size matter?," Journal of Intermational Economics, 1998, 44, 231-255.

Antweiler, Werner and Daniel Trefler, "Increasing Returns and All That: A View from Trade," American Economic Review, 2002, 92 (1), 93-119.

Basu, Susanto and John G. Fernald, "Returns to Scale in U.S. Production: Estimates and Implications," Journal of Political Economy, 1997, 105 (2), 249-283.

Behrens, Kristian, Andrea R. Lamorgese, Gianmarco Ottaviano, and Takatoshi Tabuchi, "'Beyond the home market effect: Market size and specialization in a multicountry world," Journal of International Economics, 2009, 79 (2), 259-265.

Brulhart, Marius and Federico Trionfetti, "A test of trade theories when expenditure is home biased," European Economic Review, 2009, 53 (7), 830-845.

Caron, Justin, Thibault Fally, and Ana Cecilia Fieler, "Home-market effects on innovation," mimeo UC Berkeley, 2015.

Cleave, TL, Peptic Ulcer: A New Approach to its Causation, Prevention, and Arrest, Based on Human Evolution, Bristol: Great Britain: John Wright and Sons Ltd, 1962.

Crozet, Mathieu and Federico Trionfetti, "Trade costs and the home market effect," Journal of Intermational Economics, 2008, 76, 309-321.

Davis, Donald R., "The home market, trade and industrial structure," American Economic Review, 1998, 88 (5), 1264-1276.

- and David Weinstein, "Does Economic Geography Matter for International Specialization?," NBER Working Paper 5706, 1996.

_ and _ , "Economic geography and regional production structure: an empirical investigation," European Economic Review, 1999, 43, 379-407.

_ and _ ,"Market access, economic geography and comparative advantage: an empirical test," Journal of Intermational Economics, 2003, 59, 1-23. 
Dingel, Jonathan I., "The Determinants of Quality Specialization," 2015. mimeo University of Chicago.

Eaton, Jonathan and Samuel Kortum, "Technology, Geography and Trade," Econometrica, 2002, 70 (5), 1741-1779.

Ethier, Wilfred J., “Decreasing Costs in International Trade and Frank Graham's Argument for Protection," Econometrica, 1982, 50 (5), 1243-1268.

Fajgelbaum, Pablo, Gene M. Grossman, and Elhanan Helpman, "Income Distribution, Product Quality, and International Trade," Journal of Political Economy, 2011, 119 (4), 721-765.

_, , , and _ , "A Linder Hypothesis for Foreign Direct Investment," Review of Economic Studies, 2015, 82, 83-121.

Feenstra, Robert C., James R. Markusen, and Andrew K. Rose, "Using the Gravity Equation to Differentiate among Alternative Theories of Trade," Canadian Journal of Economics, 2001, 34 (2), 430-447.

Fujita, Masahisa, Paul R. Krugman, and Anthony Venables, The Spatial Economy: Cities, Regions, and International Trade, MIT press, 2001.

Gali, Jordi and Tommaso Monacelli, "Monetary Policy and Exchange Rate Volatility in a Small Open Economy," Review of Economic Studies, 2005, 72, 707-734.

Hanson, Gordon H. and Chong Xiang, "The home market effect and bilateral trade patterns," American Economic Review, 2004, 94 (4), 1108-1129.

Hara, Takuji, Innovation in the Pharmaceutical Industry: The Process of Drug Discovery and Development, Cheltenham: UK: Edward Elgar, 2003.

Head, Keith and John Ries, "Increasing Returns versus National Product Differentiation as an Explanation for the Pattern of U.S.-Canada Trade," American Economic Review, 2001, 91 (4), 858-876.

- and Thierry Mayer, The Empirics of Agglomeration and Trade, Vol. 4 of Handbook of Regional and Urban Economic, Amsterdam: Holland: Elsevier, 2004.

_ and _ , "The erosion of colonial trade linkages after independence," Journal of International Economics, 2010, 81 (1), 1-14. 
_ and _ , Gravity Equations: Toolkit, Cookbook, Workhorse, Vol. 4 of Handbook of International Economics, Elsevier, 2013.

_ , - , and John Ries, "On the Pervasiveness of Home Market Effects," Economica, 2002, $69,371-390$.

Helpman, Elhanan and Paul Krugman, Market Structure and Foreign Trade: Increasing Returns, Imperfect Competition, and the International Economy, Cambridge, Massachusetts: MIT Press, 1985.

- and Paul R. Krugman, Trade Policy and Market Structure, Cambridge, Massachussetts: MIT Press, 1989.

Holmes, Thomas J. and John J. Stevens, "Does home market size matter for the pattern of trade?," Journal of International Economics, 2005, 65, 489-505.

Krugman, Paul, "Scale Economies, Product Differentiation, and the Pattern of Trade," The American Economic Review, 1980, 70 (5), 950-959.

Krugman, Paul R., Import protection as export promotion: international competition in the presence of oligopoly and economies of scale Monopolistic competition in international trade, Oxford University Press, 1984.

Lichtenberg, Frank R., "The Allocation of Publicly Funded Biomedical Research," in David M. Cutler and Ernst R. Berndt, eds., Medical Care Output and Productivity, University of Chicago Press, 2001, pp. 565-590.

Linder, Staffan B., An Essay on Trade and Transformation, Uppsala: Almqvist and Wiksells, 1961.

Lundback, Erik J. and Johan Torstensson, "Demand, comparative advantage and economic geography in international trade: Evidence from the OECD," Review of World Economics, 1998, 134 (2), 230-249.

Manski, Charles F., "Identification of Endogenous Social Effects: The Reflection Problem," Review of Economic Studies, 1993, 60 (3), 531-542.

Matsuyama, Kiminori, "The Home Market Effect and the Pattern of Trade Between Rich and Poor Countries," mimeo Northwestern University, 2015.

Ramondo, Natalia and Andres Rodríguez-Clare, "Trade, Multinational Production, and the Gains from Openness," Journal of Political Economy, 2013, 121 (2), 273-322. 
Scott Morton, Fiona and Margaret Kyle, Markets for Pharmaceutical Products, Vol. 2 of Handbook of Health Economics, Elsevier, 2012.

Shea, John, “Do Supply Curves Slope Up?," Quarterly Journal of Economics, 1993, 108 (1), $1-32$.

Thomas, Lacy Glenn, "Implicit Industrial Policy: The Triumph of Britain and the Failure of France in Global Pharmaceuticals," Industrial and Corporate Change, 1994, 3 (2), $451-489$.

Trionfetti, Federico, "Using Home-Biased Demand to Test Trade Theories," Review of World Economics, 2001, 137 (3), 404-426.

Vernon, Raymond, "International Investment and International Trade in the Product Cycle," Quarterly Journal of Economics, 1966, 80 (2), 190-207.

Weder, Rolf, "Comparative home-market advantage: An empirical analysis of British and American exports," Review of World Economics, 2003, 139 (2), 220-247. 


\section{A Multinational Enterprises (Section 3.1)}

In this appendix, we illustrate how to incorporate multinational production into our basic environment. Following Ramondo and Rodríguez-Clare (2013), suppose that each firm headquartered in country $i$ that sells drugs targeting disease $n$ in country $j \neq i$ can choose the country $l$ in which its production takes place. If $l=i$, then the firm exports, if $l=j$, it engages in horizontal FDI, and if $l \neq i, j$, it engages in platform FDI. At each production site $l$, we assume that the marginal cost of a firm from country $i$ serving country $j$ is constant and given by

$$
c_{i j}^{n}(l)=c\left(\eta_{i}^{n} s_{i}^{n}\right) \kappa_{i j}^{n}(l),
$$

where $c\left(s_{i}^{n} / \eta_{i}^{n}\right)$ captures the extent of economies of scale, which depends on the total supply of drugs targeting disease $n$ in country $i$, and $\kappa_{i j}^{n}(l)$ captures the costs of local inputs in country $l$, the potential frictions associated with replicating Home's technology in country $l$, as well as the trade costs associated with shipping goods from country $l$ to country $j$. In equilibrium, all firms from country $i$ will serve country $j$ from the location $l$ that minimizes $c_{i j}^{n}(l)$ across all $l$ and charge an equilibrium price,

$$
p_{i j}^{n}=\min _{l}\left\{c_{i j}^{n}(l)\right\}
$$

Now set $p_{i}^{n} \equiv c\left(s_{i}^{n} / \eta_{i}^{n}\right)$ and $\tau_{i j}^{n}=\min _{l}\left\{\kappa_{i j}^{n}(l)\right\}$. By construction, equation (4) holds with $s(\cdot)=$ $c^{-1}(\cdot)$, whereas equation (5) derives from equations (A.1) and (A.2).

\section{B Log-Linearization (Section 3.2)}

In this appendix, we derive equation (7) by log-linearizing our model around a symmetric equilibrium with $\theta_{j}^{n}=1$ for all $j$ and $n ; \eta_{i}^{n}=1$ for all $i$ and $n ; \tau_{i i}^{n}=1$ for all $i$ and $n$ and $\tau_{i j}^{n}=\tau$ for all $n$ and $i \neq j$. We let $D, d$, and $x$ denote aggregate drug consumption, the per disease expenditure on domestic drugs, and the per disease expenditure on drugs form any other country, respectively, in the symmetric equilibrium. In turn, we let $\lambda=d /(d+(I-1) x)$ denote the share of expenditure on domestic drugs, with $I$ the total number of countries. In the symmetric equilibrium, $\lambda$ is also equal to the share of revenue on the domestic market. Finally, without loss of generality, we normalize all drug prices, $p_{i}^{n}$, to one in the symmetric equilibrium and we let $P_{\text {dis }}$ and $P_{\text {agg }}$ denote the the common values of $P_{j}^{n}$ and $P_{j}$ across all disease-destination pairs and destinations, respectively.

Up to a first-order approximation, for all $n$ and $i \neq j$, equations (1), (2), and (5) imply

$$
\begin{aligned}
\ln x_{i j}^{n}= & \ln x+\ln \theta_{j}^{n}-\epsilon^{x}\left(\ln p_{i}^{n}-\ln P_{j}^{n}+\ln P_{d i s}+\ln \tau_{i j}^{n}-\ln \tau\right) \\
& -\epsilon^{D}\left(\ln P_{j}^{n}-\ln P_{d i s}-\ln P_{j}+\ln P_{a g g}\right)+\ln D_{j}-\ln D+\ln p_{i}^{n}+\ln \tau_{i j}^{n}-\ln \tau .
\end{aligned}
$$

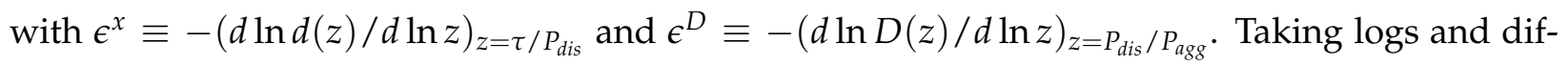


ferentiating equation (3) around the symmetric equilibrium, we also get

$$
\frac{\partial \ln P_{j}^{n}}{\partial \ln p_{i j}^{n}}= \begin{cases}\frac{1-\lambda}{I-1} \frac{\left(1-\epsilon^{x}\right)}{1-\lambda \epsilon^{d}-(1-\lambda) \epsilon^{x}} & , \text { if } i \neq j \\ \frac{\lambda\left(1-\epsilon^{d}\right)}{1-\lambda \epsilon^{d}-(1-\lambda) \epsilon^{x}} & , \text { if } i=j\end{cases}
$$

with $\epsilon^{d} \equiv-(d \ln d(z) / d \ln z)_{z=1 / P_{d i s}}$. Up to a first-order approximation, we therefore have

$$
\ln P_{j}^{n}=\ln P_{d i s}+\frac{\lambda\left(1-\epsilon^{d}\right)}{1-\lambda \epsilon^{d}-(1-\lambda) \epsilon^{x}} \ln p_{j}^{n}+\frac{1-\lambda}{I-1} \frac{\left(1-\epsilon^{x}\right)}{1-\lambda \epsilon^{d}-(1-\lambda) \epsilon^{x}} \sum_{l \neq j}\left(\ln p_{l}^{n}+\ln \tau_{l j}^{n}-\ln \tau\right) .
$$

Combining the previous expression with equation (B.1), we obtain

$$
\begin{aligned}
\ln x_{i j}^{n}= & \kappa_{j}+\ln \theta_{j}^{n}+\left(1-\epsilon^{x}+\frac{1-\lambda}{I-1} \frac{\left(1-\epsilon^{x}\right)\left(\epsilon^{x}-\epsilon^{D}\right)}{1-\lambda \epsilon^{d}-(1-\lambda) \epsilon^{x}}\right) \ln p_{i}^{n}+\frac{\lambda\left(1-\epsilon^{d}\right)\left(\epsilon^{x}-\epsilon^{D}\right)}{1-\lambda \epsilon^{d}-(1-\lambda) \epsilon^{x}} \ln p_{j}^{n} \\
& +\frac{1-\lambda}{I-1} \frac{\left(1-\epsilon^{x}\right)\left(\epsilon^{x}-\epsilon^{D}\right)}{1-\lambda \epsilon^{d}-(1-\lambda) \epsilon^{x}} \sum_{l \neq i, j}\left(\ln p_{l}^{n}+\ln \tau_{l j}^{n}\right)+\left(1-\epsilon^{x}+\frac{1-\lambda}{I-1} \frac{\left(1-\epsilon^{x}\right)\left(\epsilon^{x}-\epsilon^{D}\right)}{1-\lambda \epsilon^{d}-(1-\lambda) \epsilon^{x}}\right) \ln \tau_{i j}^{n},
\end{aligned}
$$

with

$$
\kappa_{j} \equiv \ln x+\left(\epsilon^{x}-\frac{(1-\lambda)\left(1-\epsilon^{x}\right)}{1-\lambda \epsilon^{d}-(1-\lambda) \epsilon^{x}}\left(\epsilon^{x}-\epsilon^{D}\right)-1\right) \ln \tau+\epsilon^{D}\left(\ln P_{j}-\ln P_{a g g}\right)+\ln D_{j}-\ln D .
$$

For $i=j$, the same logic implies

$$
\begin{aligned}
\ln x_{i i}^{n}=\tilde{\kappa}_{i}+\ln \theta_{i}^{n}+\left(1-\epsilon^{d}+\frac{\lambda\left(1-\epsilon^{d}\right)\left(\epsilon^{d}-\epsilon^{D}\right)}{1-\lambda \epsilon^{d}-(1-\lambda) \epsilon^{x}}\right) \ln p_{i}^{n} \\
+\frac{1-\lambda}{I-1} \frac{\left(1-\epsilon^{x}\right)\left(\epsilon^{d}-\epsilon^{D}\right)}{1-\lambda \epsilon^{d}-(1-\lambda) \epsilon^{x}} \sum_{l \neq i}\left(\ln p_{l}^{n}+\ln \tau_{l i}^{n}\right),
\end{aligned}
$$

with

$$
\tilde{\kappa}_{i} \equiv \ln d-\frac{(1-\lambda)\left(1-\epsilon^{x}\right)}{1-\lambda \epsilon^{d}-(1-\lambda) \epsilon^{x}}\left(\epsilon^{d}-\epsilon^{D}\right) \ln \tau+\epsilon^{D}\left(\ln P_{j}-\ln P_{a g g}\right)+\ln D_{j}-\ln D .
$$

Next, let us compute producer prices around a symmetric equilibrium. Up to a first-order approximation, for all $i$ and $n$, equations (4), (5), and (6) imply

$$
\left(1+\epsilon^{s}\right) \ln p_{i}^{n}+\ln \eta_{i}^{n}=\lambda\left(\ln x_{i i}^{n}-\ln d\right)+\frac{(1-\lambda)}{I-1} \sum_{j \neq i}\left(\ln x_{i j}^{n}-\ln x\right),
$$

with $\epsilon^{\mathcal{S}} \equiv(d \ln s(z) / d \ln z)_{z=1}$. Together with equations (B.2) and (B.3), this implies

$$
\left(\epsilon^{\mathcal{S}}+\epsilon^{w}\right) \ln p_{i}^{n}-\frac{\left(\epsilon^{w}-\epsilon^{D}\right)}{I-1} \sum_{l \neq i} \ln p_{l}^{n}=\lambda \ln \theta_{i}^{n}+\frac{(1-\lambda)}{I-1} \sum_{j \neq i} \ln \theta_{j}^{n}+\xi_{i}^{n},
$$


with

$$
\begin{aligned}
\epsilon^{w} & \equiv \lambda \epsilon^{d}+(1-\lambda) \epsilon^{x}-\frac{\lambda^{2}\left(1-\epsilon^{d}\right)\left(\epsilon^{d}-\epsilon^{D}\right)}{1-\lambda \epsilon^{d}-(1-\lambda) \epsilon^{x}}-\frac{\left(1-\epsilon^{x}\right)\left(\epsilon^{x}-\epsilon^{D}\right)}{1-\lambda \epsilon^{d}-(1-\lambda) \epsilon^{x}} \frac{(1-\lambda)^{2}}{I-1}, \\
\xi_{i}^{n} & \equiv \lambda\left(\tilde{\kappa}_{i}-\ln d\right)+\frac{(1-\lambda)}{I-1} \sum_{j \neq i}\left(\kappa_{j}-\ln x\right)-\ln \eta_{i}^{n} \\
& +\lambda \frac{1-\lambda}{I-1} \frac{\left(1-\epsilon^{x}\right)\left(\epsilon^{d}-\epsilon^{D}\right)}{1-\lambda \epsilon^{d}-(1-\lambda) \epsilon^{x}} \sum_{l \neq i} \ln \tau_{l i}^{n}+\frac{(1-\lambda)^{2}}{(I-1)^{2}} \frac{\left(1-\epsilon^{x}\right)\left(\epsilon^{x}-\epsilon^{D}\right)}{1-\lambda \epsilon^{d}-(1-\lambda) \epsilon^{x}} \sum_{j \neq i} \sum_{l \neq i, j} \ln \tau_{l j}^{n} \\
& +\frac{(1-\lambda)}{I-1}\left(1-\epsilon^{x}+\frac{1-\lambda}{I-1} \frac{\left(1-\epsilon^{x}\right)\left(\epsilon^{x}-\epsilon^{D}\right)}{1-\lambda \epsilon^{d}-(1-\lambda) \epsilon^{x}}\right) \sum_{j \neq i} \ln \tau_{i j}^{n} .
\end{aligned}
$$

The solution to the previous system is given by

$$
\ln p_{i}^{n}=\frac{\left(\lambda-\frac{1-\lambda}{I-1}\right)}{\epsilon^{\mathcal{S}}+\epsilon^{w}+\frac{\epsilon^{w}-\epsilon^{D}}{I-1}} \ln \theta_{i}^{n}+\frac{\xi_{i}^{n}}{\epsilon^{\mathcal{S}}+\epsilon^{w}+\frac{\epsilon^{w}-\epsilon^{D}}{I-1}}+\zeta^{n},
$$

with

$$
\zeta^{n} \equiv \frac{\left(\frac{1-\lambda}{I-1}+\frac{\epsilon^{w}-\epsilon^{D}}{\left(\epsilon^{s}+\epsilon^{D}\right)(I-1)}\right) \sum_{j} \ln \theta_{j}^{n}+\frac{1}{\left(\epsilon^{s}+\epsilon^{D}\right)} \frac{\left(\epsilon^{w}-\epsilon^{D}\right)}{I-1} \sum_{l} \xi_{l}^{n}}{\epsilon^{\mathcal{S}}+\epsilon^{w}+\frac{\epsilon^{w}-\epsilon^{D}}{I-1}}
$$

Combining equations (B.2) and (B.4), we obtain, for any $n$ and $i \neq j$,

$$
\ln x_{i j}^{n}=\delta_{i j}+\delta^{n}+\beta_{M} \ln \theta_{j}^{n}+\beta_{X} \ln \theta_{i}^{n}+\varepsilon_{i j}^{n}
$$


with

$$
\begin{aligned}
& \delta_{i j} \equiv \frac{\left(1-\epsilon^{x}+\frac{1-\lambda}{I-1} \frac{\left(1-\epsilon^{x}\right)\left(\epsilon^{x}-\epsilon^{D}\right)}{1-\lambda \epsilon^{d}-(1-\lambda) \epsilon^{x}}\right) \bar{\xi}_{i}+\frac{\left(1-\epsilon^{d}\right)\left(\epsilon^{x}-\epsilon^{D}\right)}{1-\lambda \epsilon^{d}-(1-\lambda) \epsilon^{x}} \lambda \bar{\xi}_{j}+\frac{1-\lambda}{I-1} \frac{\left(1-\epsilon^{x}\right)\left(\epsilon^{x}-\epsilon^{D}\right)}{1-\lambda \epsilon^{d}-(1-\lambda) \epsilon^{x}} \sum_{l \neq i, j} \bar{\xi}_{l}}{\epsilon^{S}+\epsilon^{w}+\frac{\epsilon^{w}-\epsilon^{D}}{I-1}} \\
& +\left(1-\epsilon^{x}+\frac{1-\lambda}{I-1} \frac{\left(1-\epsilon^{x}\right)\left(\epsilon^{x}-\epsilon^{D}\right)}{1-\lambda \epsilon^{d}-(1-\lambda) \epsilon^{x}}\right)\left(\overline{\ln \tau_{i j}}\right)+\frac{1-\lambda}{I-1} \frac{\left(1-\epsilon^{x}\right)\left(\epsilon^{x}-\epsilon^{D}\right)}{1-\lambda \epsilon^{d}-(1-\lambda) \epsilon^{x}} \sum_{l \neq i, j}\left(\overline{\ln \tau_{l j}}\right)+\kappa_{j}, \\
& \delta^{n} \equiv \frac{1-\lambda}{I-1} \frac{\left(1-\epsilon^{x}\right)\left(\epsilon^{x}-\epsilon^{D}\right)}{1-\lambda \epsilon^{d}-(1-\lambda) \epsilon^{x}}\left(\lambda-\frac{1-\lambda}{I-1}\right)\left(\sum_{l} \ln \theta_{l}^{n}\right) /\left(\epsilon^{s}+\epsilon^{w}+\frac{\epsilon^{w}-\epsilon^{D}}{I-1}\right)+\left(1-\epsilon^{D}\right) \zeta^{n}, \\
& \beta_{M} \equiv 1+\frac{\left(\epsilon^{x}-\epsilon^{D}\right)\left(\frac{\lambda\left(1-\epsilon^{d}\right)}{1-\lambda \epsilon^{d}-(1-\lambda) \epsilon^{x}}-\frac{1-\lambda}{I-1} \frac{\left(1-\epsilon^{x}\right)}{1-\lambda \epsilon^{d}-(1-\lambda) \epsilon^{x}}\right)\left(\lambda-\frac{1-\lambda}{I-1}\right)}{\epsilon^{\mathcal{S}}+\epsilon^{w}+\frac{\epsilon^{w}-\epsilon^{D}}{I-1}}, \\
& \beta_{X} \equiv \frac{\left(1-\epsilon^{x}\right)\left(\lambda-\frac{1-\lambda}{I-1}\right)}{\epsilon^{\mathcal{S}}+\epsilon^{w}+\frac{\epsilon^{w}-\epsilon^{D}}{I-1}} \\
& \varepsilon_{i j}^{n} \equiv \frac{\left(1-\epsilon^{x}+\frac{1-\lambda}{I-1} \frac{\left(1-\epsilon^{x}\right)\left(\epsilon^{x}-\epsilon^{D}\right)}{1-\lambda \epsilon^{d}-(1-\lambda) \epsilon^{x}}\right)\left(\xi_{i}^{n}-\bar{\xi}_{i}\right)+\frac{\left(1-\epsilon^{d}\right)\left(\epsilon^{x}-\epsilon^{D}\right)}{1-\lambda \epsilon^{d}-(1-\lambda) \epsilon^{x}} \lambda\left(\xi_{j}^{n}-\bar{\zeta}_{j}\right)+\frac{1-\lambda}{I-1} \frac{\left(1-\epsilon^{x}\right)\left(\epsilon^{x}-\epsilon^{D}\right)}{1-\lambda \epsilon^{d}-(1-\lambda) \epsilon^{x}} \sum_{l \neq i, j}\left(\xi_{l}^{n}-\bar{\zeta}_{l}\right)}{\epsilon^{\mathcal{S}}+\epsilon^{w}+\frac{\epsilon^{w}-\epsilon^{D}}{I-1}} \\
& +\frac{1-\lambda}{I-1} \frac{\left(1-\epsilon^{x}\right)\left(\epsilon^{x}-\epsilon^{D}\right)}{1-\lambda \epsilon^{d}-(1-\lambda) \epsilon^{x}} \sum_{l \neq i, j}\left(\ln \tau_{l j}^{n}-\left(\overline{\ln \tau_{l j}}\right)\right)+\left(1-\epsilon^{x}+\frac{1-\lambda}{I-1} \frac{\left(1-\epsilon^{x}\right)\left(\epsilon^{x}-\epsilon^{D}\right)}{1-\lambda \epsilon^{d}-(1-\lambda) \epsilon^{x}}\right)\left(\ln \tau_{i j}^{n}-\left(\overline{\ln \tau_{i j}}\right)\right),
\end{aligned}
$$

where $\bar{z} \equiv \frac{1}{\text { \#diseases }} \sum_{n} z^{n}$ denotes the arithmetic average of a given variable $z$ across all diseases.

\section{Robustness (Section 3.3)}

\section{C.1 Monopolistic Competition}

For each disease $n$, profit-maximization by a firm $\omega$ from country $i$ selling in country $j$ requires

$$
\frac{p_{i j}^{n}(\omega)-\tau_{i j}^{n} c_{i}^{n}}{p_{i j}^{n}(\omega)}=\frac{1}{\sigma} .
$$

Free entry requires

$$
\sum_{j}\left(p_{i j}^{n}(\omega)-\tau_{i j}^{n} c_{i}^{n}\right) d_{i j}^{n}(\omega)=f_{i}^{n}
$$

which can be rearranged as

$$
s_{i}^{n}(\omega)=\frac{f_{i}^{n}}{p_{i}^{n}(\omega)-c_{i}^{n}}
$$


with $s_{i}^{n}(\omega) \equiv \sum_{j} \tau_{i j}^{n} d_{i j}^{n}(\omega)$. By definition, we also know that

$$
\begin{aligned}
& s_{i}^{n}=\left(\int\left(s_{i}^{n}(\omega)\right)^{(\sigma-1) / \sigma} d \omega\right)^{\sigma /(\sigma-1)}, \\
& p_{i}^{n}=\left(\int\left(p_{i}^{n}(\omega)\right)^{(1-\sigma)} d \omega\right)^{1 /(1-\sigma)} .
\end{aligned}
$$

Equations (C.1), (C.2) and (C.3) imply

$$
s_{i}^{n}=\left(N_{i}^{n}\right)^{\sigma /(\sigma-1)} f_{i}^{n} /\left((\mu-1) c_{i}^{n}\right),
$$

whereas equations (C.1) and (C.4) imply

$$
p_{i}^{n}=\left(N_{i}^{n}\right)^{1 /(1-\sigma)} \mu c_{i}^{n} .
$$

Finally, note that equations (C.2) and (C.5) imply

$$
s_{i}^{n}=\left(N_{i}^{n}\right)^{\sigma /(\sigma-1)} \sum_{j} \tau_{i j}^{n} d_{i j}^{n}(\omega),
$$

for any firm $\omega$, whereas equations (13), (C.1), and (C.6) imply

$$
d_{i j}^{n}(\omega)=\left(N_{i}^{n}\right)^{-\sigma /(\sigma-1)} d_{i j}^{n}
$$

Equation (6) follows from the two previous expressions.

\section{C.2 Bertrand Oligopoly}

The demand for varieties produced by an individual firm, $d_{i j}^{n}(\omega)$, is given by equations (1), (2), and (13). Under the assumption of an arbitrarily large number of sectors, firms' decisions in any given sector have no effect on the country-specific demand shifters, $P_{j}$ and $D_{j}$. Hence, the elasticity of demand with respect to a firm's own price is such that

$$
\frac{d \ln d_{i j}^{n}(\omega)}{d \ln p_{i j}^{n}(\omega)}= \begin{cases}-\sigma+\frac{\left(\sigma-\epsilon^{x}\right)}{N_{i}^{n}}+\frac{\left(\epsilon^{x}-\epsilon^{D}\right)}{N_{i}^{n}} \frac{\left(1-\epsilon^{x}\right)}{1-\lambda \epsilon^{d}-(1-\lambda) \epsilon^{x}} \frac{(1-\lambda)}{I-1} & , \text { if } i \neq j \\ -\sigma+\frac{\left(\sigma-\epsilon^{d}\right)}{N_{i}^{n}}+\frac{\left(\epsilon^{d}-\epsilon^{D}\right)}{N_{i}^{n}} \frac{\left(1-\epsilon^{d}\right)}{1-\lambda \epsilon^{d}-(1-\lambda) \epsilon^{x}} \lambda & , \text { if } i=j .\end{cases}
$$

Under the additional assumption that $\epsilon^{D}=\epsilon^{x}=\epsilon^{d}$, the elasticity of demand simplifies into

$$
\frac{d \ln d_{i j}^{n}(\omega)}{d \ln p_{i j}^{n}(\omega)}=-\sigma+\frac{\left(\sigma-\epsilon^{d}\right)}{N_{i}^{n}}
$$


For each disease $n$, profit-maximization by a firm $\omega$ from country $i$ selling in country $j$ therefore now requires

$$
\frac{p_{i j}^{n}(\omega)-\tau_{i j}^{n} c_{i}^{n}}{p_{i j}^{n}(\omega)}=\frac{1}{\sigma-\left(\sigma-\epsilon^{d}\right) / N_{i}^{n}} .
$$

The free entry condition (C.2) remains unchanged, whereas equations (C.3) and (C.4) still hold with $\sum$ rather than $\int$.

Equations (C.2), (C.3), and (C.7) now imply

$$
s_{i}^{n}=\left(N_{i}^{n}\right)^{\sigma /(\sigma-1)} f_{i}^{n} /\left(\left(\mu\left(N_{i}^{n}\right)-1\right) c_{i}^{n}\right),
$$

with $\mu\left(N_{i}^{n}\right) \equiv \frac{\left(\left(1-1 / N_{i}^{n}\right) \sigma+\epsilon^{d} / N_{i}^{n}\right)}{\left(1-1 / N_{i}^{n}\right) \sigma+\epsilon^{d} / N_{i}^{n}-1}$, whereas equations (C.4) and (C.7) imply

$$
p_{i}^{n}=\left(N_{i}^{n}\right)^{1 /(1-\sigma)} \mu\left(N_{i}^{n}\right) c_{i}^{n}
$$

\section{C.3 Monopoly}

The first-order conditions associated with profit maximization imply

$$
\begin{aligned}
\frac{p_{i j}^{n}-\tau_{i j}^{n} c_{i}^{n}}{p_{i j}^{n}} & =\frac{1}{\epsilon^{d}}, \\
s_{i}^{n} & =-\eta_{i}^{n} f^{\prime}\left(c_{i}^{n}\right),
\end{aligned}
$$

with $s_{i}^{n}=\sum_{j} \tau_{i j}^{n} d_{i j}^{n}$ the total quantity produced by the monopolist. Combining the two previous expressions, we immediately obtain

$$
s_{i}^{n}=-\eta_{i}^{n} f^{\prime}\left(\left(\epsilon^{d}-1\right) p_{i}^{n} / \epsilon^{d}\right) .
$$

\section{Bilateral Sales (Section 6.1)}

In Appendix B, we have already shown that

$$
\begin{aligned}
\ln x_{i j}^{n}= & \alpha_{j}+\ln \theta_{j}^{n}+\left(1-\epsilon^{x}+\frac{1-\lambda}{I-1} \frac{\left(1-\epsilon^{x}\right)\left(\epsilon^{x}-\epsilon^{D}\right)}{1-\lambda \epsilon^{d}-(1-\lambda) \epsilon^{x}}\right) \ln p_{i}^{n}+\frac{\lambda\left(1-\epsilon^{d}\right)\left(\epsilon^{x}-\epsilon^{D}\right)}{1-\lambda \epsilon^{d}-(1-\lambda) \epsilon^{x}} \ln p_{j}^{n} \\
& +\frac{1-\lambda}{I-1} \frac{\left(1-\epsilon^{x}\right)\left(\epsilon^{x}-\epsilon^{D}\right)}{1-\lambda \epsilon^{d}-(1-\lambda) \epsilon^{x}} \sum_{l \neq i, j}\left(\ln p_{l}^{n}+\ln \tau_{l j}^{n}\right)+\left(1-\epsilon^{x}+\frac{1-\lambda}{I-1} \frac{\left(1-\epsilon^{x}\right)\left(\epsilon^{x}-\epsilon^{D}\right)}{1-\lambda \epsilon^{d}-(1-\lambda) \epsilon^{x}}\right) \ln \tau_{i j}^{n} .
\end{aligned}
$$

This can be rearranged as

$$
\ln x_{i j}^{n}=\alpha_{j}^{n}+\left(1-\epsilon^{x}\right) \ln p_{i}^{n}+\left(1-\epsilon^{x}\right) \ln \tau_{i j}^{n},
$$


with $\alpha_{j}^{n} \equiv \alpha_{j}+\ln \theta_{j}^{n}+\frac{\lambda\left(1-\epsilon^{d}\right)\left(\epsilon^{x}-\epsilon^{D}\right)}{1-\lambda \epsilon^{d}-(1-\lambda) \epsilon^{x}} \ln p_{j}^{n}+\frac{1-\lambda}{I-1} \frac{\left(1-\epsilon^{x}\right)\left(\epsilon^{x}-\epsilon^{D}\right)}{1-\lambda \epsilon^{d}-(1-\lambda) \epsilon^{x}} \sum_{l \neq j}\left(\ln p_{l}^{n}+\ln \tau_{l j}^{n}\right)$.

\section{E Additional empirical analysis}

Table E.1 establishes that predicted disease burden is indeed a strong predictor of a country's actual disease burden, even conditional on country and disease fixed-effects (which we condition on whenever we use the predicted disease burden in our tests of the home-market effect). Column (1) shows that the predictive power of a country's demographic composition, interacted with the demographic disease pattern of a disease, is substantial within a sample of country-disease observations that sell in at least one destination country (that is, countries $i$ with $\sum_{j} x_{i j}^{n}>0$ ). And column (2) establishes the same feature in a sample of purchasing country-disease observations (those countries $j$ with $\sum_{i} x_{i j}^{n}>0$ ).

Table E.1: Predicting disease burden using demographic variation

\begin{tabular}{lcc}
\hline & \multicolumn{2}{c}{$\log ($ disease burden $)$} \\
\cline { 2 - 3 } & $(1)$ & $(2)$ \\
\hline $\log ($ predicted disease burden $)$ & 1.618 & 1.769 \\
& $(0.355)$ & $(0.370)$ \\
\hline Sample of origin countries $\left(i, n\right.$ such that $\left.\sum_{j} X_{i j}^{n}>0\right)$ & $\checkmark$ & \\
Sample of destination countries $\left(j, n\right.$ such that $\left.\sum_{i} X_{i j}^{n}>0\right)$ & & $\checkmark$ \\
\hline Adjusted $R^{2}$ & 0.886 & 0.900 \\
Observations & 2,316 & 2,930 \\
\hline
\end{tabular}

Notes: For details on construction of variables, sample restrictions see notes to Table 3. Standard errors in parentheses are two-way clustered at country and disease levels. All specifications control for country and disease fixed-effects. 